\title{
Review \\ Engineering the 2-Oxoglutarate Dehydrogenase Complex to Understand Catalysis and Alter Substrate Recognition
}

\author{
Joydeep Chakraborty ${ }^{1,2, *(\mathbb{D}) \text {, Natalia Nemeria }}{ }^{3}$, Yujeong Shim ${ }^{2}$, Xu Zhang ${ }^{3}$, Elena L. Guevara ${ }^{3}$, Hetal Patel ${ }^{3}$, \\ Edgardo T. Farinas $2, *$ (D) and Frank Jordan $3, *$ (D)
}

1 Texas A\&M Agrilife Research, Texas A\&M University, College Station, TX 77843, USA

2 Department of Chemistry and Environmental Science, New Jersey Institute of Technology, Newark, NJ 07102, USA; djs45@njit.edu

3 Department of Chemistry, Rutgers University, Newark, NJ 07103, USA; nemeria@newark.rutgers.edu (N.N.); xz364@scarletmail.rutgers.edu (X.Z.); elenague@scarletmail.rutgers.edu (E.L.G.); hetalben@scarletmail.rutgers.edu (H.P.)

* Correspondence: joydeep.c2019@tamu.edu (J.C.); edgardo.t.farinas@njit.edu (E.T.F.); frjordan@newark.rutgers.edu (F.J.); Tel.: +1-979-458-8693 (J.C.); +1-973-642-7353 (E.T.F.); +1-973-353-5470 (F.J.)

\section{check for} updates

Citation: Chakraborty, J.; Nemeria, N.; Shim, Y.; Zhang, X.; Guevara, E.L.; Patel, H.; Farinas, E.T.; Jordan, F. Engineering the 2-Oxoglutarate Dehydrogenase Complex to Understand Catalysis and Alter

Substrate Recognition. Reactions 2022, 3, 139-159. https://doi.org/10.3390/ reactions 3010011

Academic Editors: Karen Draths and Dmitry Yu. Murzin

Received: 11 October 2021

Accepted: 28 January 2022

Published: 1 February 2022

Publisher's Note: MDPI stays neutral with regard to jurisdictional claims in published maps and institutional affiliations.

Copyright: (C) 2022 by the authors. Licensee MDPI, Basel, Switzerland. This article is an open access article distributed under the terms and conditions of the Creative Commons Attribution (CC BY) license (https:// creativecommons.org/licenses/by/ $4.0 /)$.

\begin{abstract}
The E. coli 2-oxoglutarate dehydrogenase complex (OGDHc) is a multienzyme complex in the tricarboxylic acid cycle, consisting of multiple copies of three components, 2-oxoglutarate dehydrogenase (E1o), dihydrolipoamide succinyltransferase (E2o) and dihydrolipoamide dehydrogenase (E3), which catalyze the formation of succinyl-CoA and $\mathrm{NADH}\left(+\mathrm{H}^{+}\right)$from 2-oxoglutarate. This review summarizes applications of the site saturation mutagenesis (SSM) to engineer E. coli OGDHc with mechanistic and chemoenzymatic synthetic goals. First, E1o was engineered by creating SSM libraries at positions His260 and His298. Variants were identified that: (a) lead to acceptance of substrate analogues lacking the 5-carboxyl group and (b) performed carboligation reactions producing acetoin-like compounds with good enantioselectivity. Engineering the E2o catalytic (core) domain enabled (a) assignment of roles for pivotal residues involved in catalysis, (b) re-construction of the substrate-binding pocket to accept substrates other than succinyllysyldihydrolipoamide and (c) elucidation of the mechanism of trans-thioesterification to involve stabilization of a tetrahedral oxyanionic intermediate with hydrogen bonds by His375 and Asp374, rather than general acid-base catalysis which has been misunderstood for decades. The E. coli OGDHc is the first example of a 2-oxo acid dehydrogenase complex which was evolved to a 2-oxo aliphatic acid dehydrogenase complex by engineering two consecutive E1o and E2o components.
\end{abstract}

Keywords: multienzyme complex; site saturation mutagenesis; catalysis; thiamin diphosphate; chemoenzymatic synthesis; carboligation

\section{Introduction \\ 1.1. Strategies for Protein Engineering}

To achieve altered substrate specificity, thermostability and organic solvent stability, enzymes require engineering prior to their use as an industrial biocatalyst. At present, many enzymes which are conserved across species may not have their properties coupled. Thus, an altered substrate specificity may come at the cost of thermostability [1,2]. Rational design is one of the earliest approaches applied for enzyme engineering [3,4]. However, a detailed knowledge of enzyme structure and its active site configurations is required. The enzyme residues targeted for alteration of substrate specificity or catalysis may need to be located within $6 \AA$ or less from the substrate- or cofactor-binding sites [5-9]. At present, there is still limited knowledge about the optimization and enzymes engineering by a rational design approach. The complexity of enzyme structure-function relationships is a major limiting factor for this approach. 
These limitations could be resolved by directed evolution, where the rapid engineering of enzymes could be achieved without detailed structural knowledge. Thus, it has been reported that substitutions of the residues located far apart from the active site may contribute to substrate recognition [10-12]. The directed evolution approach could identify amino acids for substitution that would be impossible to predict by rational design. Frances Arnold et al. pioneered directed evolution in one of the earliest instances, achieving improved stability of subtilisin in dimethyl sulfoxide solvent [13-16]. Another notable example reported by Arnold et al. was the formation of novel C-Si bonds with an efficiency 15 times over that of a chemical catalyst used for the same purpose. This reaction is not found in any biological system [17]. A combination of rational design and directed evolution can also be an effective engineering strategy. For example, focused libraries could be created by using site saturation mutagenesis (SSM) with detailed knowledge about the active site structure and of the key residues responsible for substrate recognition and catalysis.

SSM is a site saturation random mutagenesis technique used in protein engineering to convert a certain amino acid to all other 19 amino acids and is employed to engineer the substrate specificity and enantioselectivity of enzymes, to improve their thermostability, as well as to introduce a new enzyme function. The application of SSM to ThDP-dependent enzymes is reviewed by Andrews and McLeish [18]. Briefly, benzoylformate decarboxylase (BFDC) catalyzes the non-oxidative decarboxylation of benzoylformate with the formation of $\mathrm{CO}_{2}$ and benzaldehyde. It also catalyzes the carboligation reaction with the formation of various 2-hydroxy (also called $\alpha$-hydroxy) ketones [18]. The combination of directed evolution, site-directed mutagenesis and SSM enabled those authors to identify the Leu476Gln and Leu476Ser BFDC variants with improved carboligase activity in organic solvents, while the Leu476Gln and Met365Leu/Leu461Ser variants could accept benzaldehyde derivatives. The SSM on Leu476 led to variants with improved carboligase activity [18]. Another ThDP-dependent enzyme, transketolase (TK), is perhaps more attractive for biocatalysis because it has stereo-specifically controlled C-C bond cleavage and formation. TK from bacterial sources has been successfully engineered to improve activity and stereoselectivity by using double-site saturation mutagenesis [19]. By using a targeted mutagenesis approach in combination with computational design, an improved thermostability of the E. coli TK was demonstrated [20]. While a detailed review of TK as a biocatalyst is beyond the scope of this review, numerous references to the engineering of E. coli TK by using novel approaches could be found in recent publications from Dalby's group [20,21] and in earlier reviews $[18,22]$.

In cases of multienzyme complexes, catalysis involves two or more enzymes, which are related through sequential, coupled, divergent or convergent reactions [23-25]. Recently, using the blueprint of natural models for enzyme co-localizations, a scaffolding approach was employed to generate macromolecular structures with improved catalytic efficiencies [26]. This approach is based on the principle of adjusting the spatial distance and molecular ratio between a few enzymes using DNA scaffolds [27], protein scaffolds [28], polymeric particle immobilizations [29], organometallic frameworks [30] and cross-linked enzyme aggregates [31]. For example, glucose oxidase and horseradish peroxidase were immobilized on a DNA scaffold and as a result they exhibited improved catalytic efficiency compared to free enzymes [27]. Recently, a strategy for the construction of a synthetic multienzyme assembly inside $E$. coli cells was reported, where the genetically engineered virus-like particles were used as protein scaffolds to assemble three enzymes in the terpene biosynthetic pathway into a multienzyme complex shifted to the production of amorpha4,11-diene, the key precursor of the antimalarial drug artemisinin [32]. At present, the co-immobilization of multiple cascade enzymes remains challenging. The different systems for the spatial organization of the multi-enzyme pathways in vitro have been discussed in detail in a recent review by M-J. Seo and C. Schmidt-Dannert [33], including nucleic acidbased scaffolds such as DNA origami, peptide and protein building blocks, self-assembling protein arrays and nanostructures and others. 
The spatial arrangement of multiple enzymes to improve their activities in cascade reactions is still debated as the scaffold used could potentially alter the enzyme activity by changing the environment surrounding the assembled enzymes (for review, see ref. [34-36]).

1.2. The E. coli 2-Oxoglutarate Dehydrogenase Complex Is a Promising Multienzyme Complex for Production of $\alpha$-Hydroxyketones and for Synthesis of Acyl CoA Analogues

The E. coli 2-oxoglutarate dehydrogenase complex (OGDHc, also known as $\alpha$-ketoglutarate dehydrogenase complex) is a highly conserved multienzyme complex in the tricarboxylic acid (TCA) cycle and catalyzes the formation of succinyl-coenzyme A (succinyl-CoA) by utilizing 2-oxoglutarate (2-OG) as a substrate according to the overall reaction in Equation (1) and mechanism in Scheme 1 [37-39].

$$
\text { 2-oxoglutarate }+\mathrm{CoA}+\mathrm{NAD}^{+} \rightarrow \text { succinyl-CoA }+\mathrm{CO}_{2}+\mathrm{NADH}+\mathrm{H}^{+}
$$

The E. coli OGDHc consists of multiple copies of three component enzymes: the thiamin diphosphate (ThDP)-dependent 2-oxoglutarate dehydrogenase (E1o; homodimer of $210 \mathrm{kDa}$; EC 1.2.4.2), dihydrolipoamide succinyltransferase (E2o; 24-mer molecular assembly with monomer of $44 \mathrm{kDa}$; EC 2.3.1.61) and dihydrolipoamide dehydrogenase (E3; homodimer of $101 \mathrm{kDa}$; EC 1.8.1.4) [40-42]. The E2o monomer has a multidomain structure consisting of the flexible lipoyl domain (LD, $\sim 8 \mathrm{kDa}$ ), a subunit binding domain $(\sim 4 \mathrm{kDa})$ to which E1o and E3 components are flexibly tethered, and the E2o core or catalytic domain (CD), which determines the stoichiometry of the E1o and E3 binding and the quaternary organization of the E. coli OGDHc (Figure 1) [39-43]. The individual E2o domains are connected by flexible linkers of $\sim 28-50$ residue long, which are rich in Ala and Pro [40-42]. The E. coli E2o assembles into a 24-mer molecular assembly with octahedral symmetry [41,44-47]. X-ray and NMR structures are available for the E. coli globular domains of the E1o [39], E2o core domain and E3 (Figure 1) [48,49]. However, there is no atomic resolution structure reported of an intact 2-oxoacid dehydrogenase complex from any sources. The earlier studies on $E$. coli pyruvate dehydrogenase complex (PDHc) and OGDHc [50,51] revealed a distant and flexible attachment of the E1 and E3 components, with gaps of 2-4 $\mathrm{nm}$ and of 3-5 $\mathrm{nm}$ between the E2o core and E1 and E3 components, respectively. Later, Murphy and Jensen showed that, in E. coli PDHc and OGDHc, the E1 and E3 components are flexibly tethered $11 \mathrm{~nm}$ from the E2o core rather than being specifically bound to the faces and edges of the E2o core as had been generally accepted [43]. More recently, low resolution cryo-EM reconstruction of the entire native $E$. coli PDHc has been reported and confirmed the presence of the outer components to the E2o core shell components; however, the individual E1p and E3 components could not be resolved [52]. The EM reconstruction of the human E2o cubic core with octahedral symmetry has been reported by two groups, providing insight into E2o trimers assembly and into formation of the multimeric core $[53,54]$. However, the electron density in the outer shell could not be assigned due to conformational flexibility [53]. In the absence of a molecular organization of 2-oxo acid dehydrogenase complexes, the molecular mechanism of intermediates channeling between components remains elusive. The generally accepted mechanism of active center coupling is that the lipoyl moieties covalently bound to the $\varepsilon$-amino group of lysine residues of the E2 lipoyl domain interact with the catalytic sites of the E1, E2 and E3 components while transferring the intermediates between the active sites in accord with the so-called "swinging arm" mechanism [55-58]. Recent studies on human PDHc by cryo-EM revealed more insight into the binding of the peripheral components and intermediates channeling and suggested the "division-of-labor" mechanism [59]. According to a "division-of-labor" mechanism, the formation of local clusters of E2p-E1p and E3BPE3 with specific functions for E1p-E2p clusters (oxidative decarboxylation of pyruvate and acetyl transfer) and for E3BP-E3 clusters (regeneration of reduced lipoamide) was suggested. The studies also suggested an asymmetric architecture of the human PDHc which could be modulated by the CoA substrate binding [59]. 
An additional complexity in our understanding of the assembly of 2-oxo acid dehydrogenase complexes originated from the remarkable ability of the bacterial OGDHc to form hybrid complexes with PDHc. Thus, in the cases of Cornybacterium glutamicum and of Mycobacterium smegmatis, the E1o and E2o components are fused into one protein named OdhA with no lipoyl domain present. Here, the lipoyl domain is shared between the OdhA and the E2p component of the PDHc [60-62]. Identification of the functional and regulatory cross-talk between the human OGDHc and 2-oxoadipate dehydrogenase (E1a) from the final degradation pathway of L-lysine, L-hydroxylysine and L-tryptophan was demonstrated at Rutgers with collaborators in vitro [63,64] and in vivo [65], suggesting that the well-known OGDHc in the TCA cycle can exist as a hybrid 2-oxoglutaric acid and 2-oxoadipic acid dehydrogenase complex where the E2o and E3 components are shared between the E1o and E1a components [65]. While challenges remain in our understanding of the assembly of 2-oxo acid dehydrogenase complexes, their most important feature for biocatalysis is that this is a self-assembled system for the channeling of intermediates.

The challenge of the studies summarized below, as undertaken jointly in the Jordan and Farinas laboratories, involved engineering of the E1o and E2o components of the $E$. coli OGDHc by using the SSM method with two goals: to understand the mechanism of the E. coli OGDHc, and to enable chemoenzymatic synthesis of chiral $\alpha$-hydroxy ketones and of acyl-CoA analogues. The authors also anticipate that this review will serve as a guide for the future engineering of the E. coli OGDHc for biocatalytic applications.

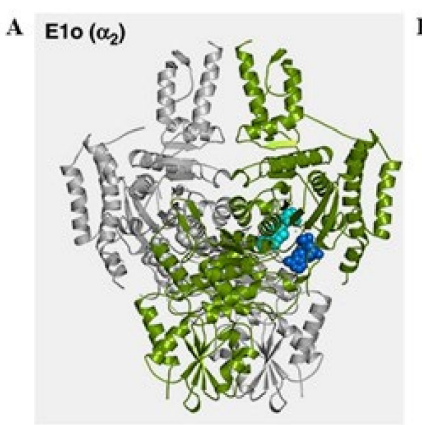

B Dihydrolipoamide succinyltransferase (E2o)

C

E3 $\left(\alpha_{2}\right)$

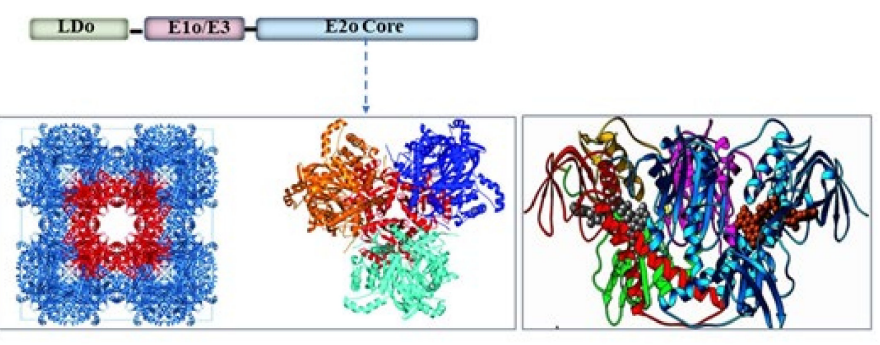

Figure 1. Structures of the globular components of the E. coli OGDH multienzyme complex. (A) X-Ray structure of the E10 $\mathrm{o}_{\Delta 77}$ homodimer with monomers shown in green and gray (PDB ID: 2JGD) [39]. (B) Structures of the E. coli E2o. (Top) Domain structure of the E. coli E2o monomer. (Bottom, right): $X$-ray structure of the E. coli E2o trimer with each monomer shown in blue, orange and cyan (PDB ID: 1C4T) [66]. (Bottom, left) The 24-mer molecular assembly of the E. coli E2o core domain (PDB ID:1scz) [49]. (C) X-ray structure of the $\mathrm{E} 3$ homodimer with each monomer shown in cyan and in blue (PDB ID: 4JDR) [48]. 


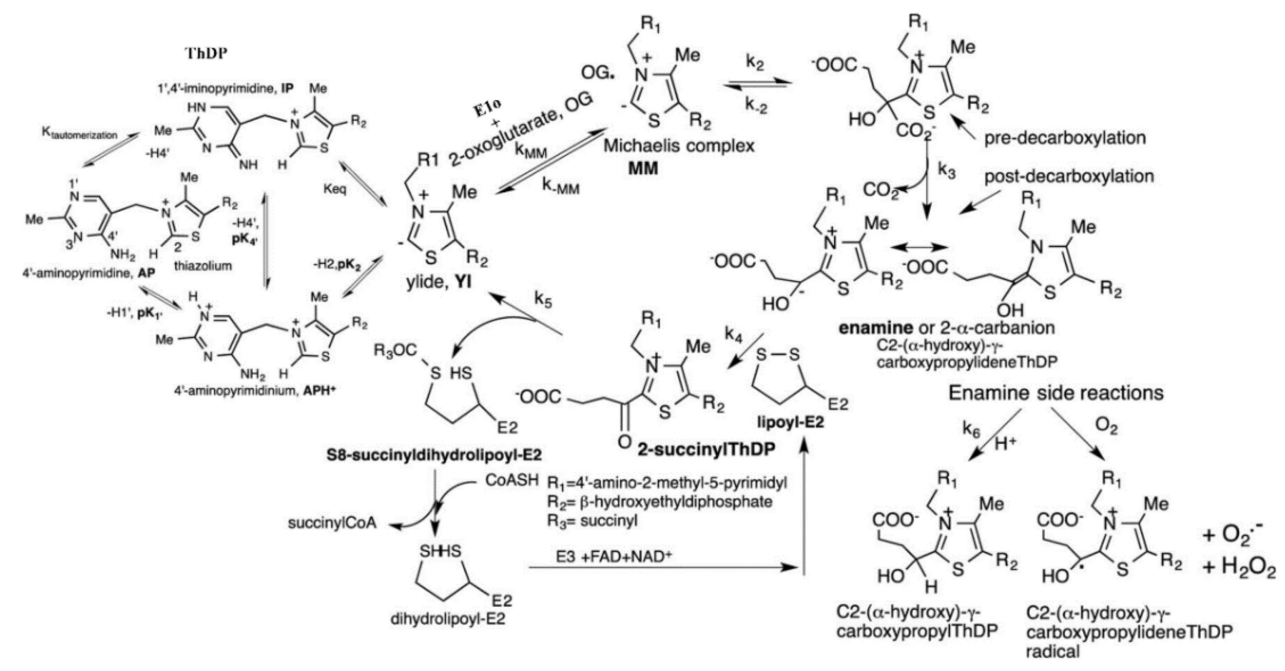

Scheme 1. Mechanism of the overall OGDHc reaction at the individual E1o, E2o and E3 components. The E1o catalyzes the decarboxylation of 2-oxoglutarate using ThDP as a cofactor with the formation of the enamine (C2- $\alpha$-carbanion) intermediate and the following transfer of the succinyl moiety to the lipoamide covalently bound to the $\varepsilon$-amino group of lysine residues of the lipoyl-E2o with the formation of S8-succinyldihydrolipoyl-E2. The E2o catalyzes the transfer of a succinyl moiety to CoA with the formation of the succinyl-CoA and of dihydrolipoyl-E2o. The dihydrolipoyl-E2o is finally re-oxidized by FAD-dependent $\mathrm{E} 3$ and $\mathrm{NAD}^{+}$yielding lipoyl-E2o and $\mathrm{NADH}\left(+\mathrm{H}^{+}\right)$[67].

\section{Engineering of the E1o Component of the E. coli OGDHc that Leads to Acceptance of Substrate Analogues Lacking the 5-Carboxyl Group}

In this work, we were interested in the engineering of the E. coli E1o active centers to accept substrates lacking the 5-carboxylate group, such as 2-oxovaleric acid (2-OV, Figure 2, top), by constructing saturation mutagenesis libraries at the E1o active site residues suggested to interact with the distal carboxylate of 2-OG [39,68].

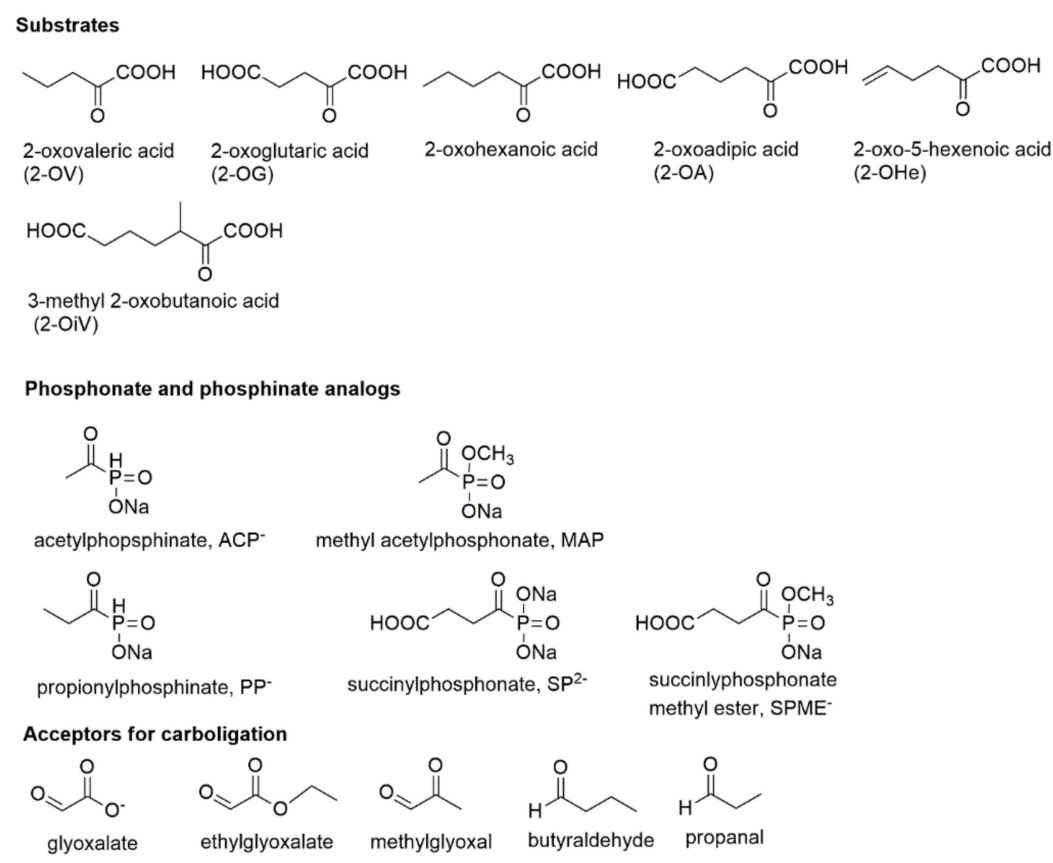

Figure 2. Structures of the substrate analogues (top), of the pre-decarboxylation intermediate (middle) and different aldehyde acceptors employed in the carboligation reaction $[69,70]$. 
According to the X-ray structure of the E. coli E1o [39], the E1o active site has three prominent His residues at positions 260, 298 and 729 (Figure 3) [39]. These His residues are positioned near the thiazolium ring of the thiamin diphosphate (ThDP) cofactor, suggesting that they are likely involved in substrate binding or catalysis. It was also reported that substitution of His260 and His298 to Ala dramatically reduced the overall activity of NADH production by E. coli OGDHc [39]. These structural and kinetic findings made these residues prime targets for E. coli E1o engineering and optimization [68]. Sitesaturation mutagenesis libraries were constructed for His260, His298 and for the double His260/His298 substitution in E. coli E1o. The libraries were then screened for the E1ospecific activity where the E2o and E3 components were replaced by an artificial electron acceptor, 2,6-dichlorophenolindophenol (DCPIP), towards 2-OG and a non-natural substrate, 2-oxovalerate (2-OV), where a nonpolar methyl group replaces the charged carboxylate.

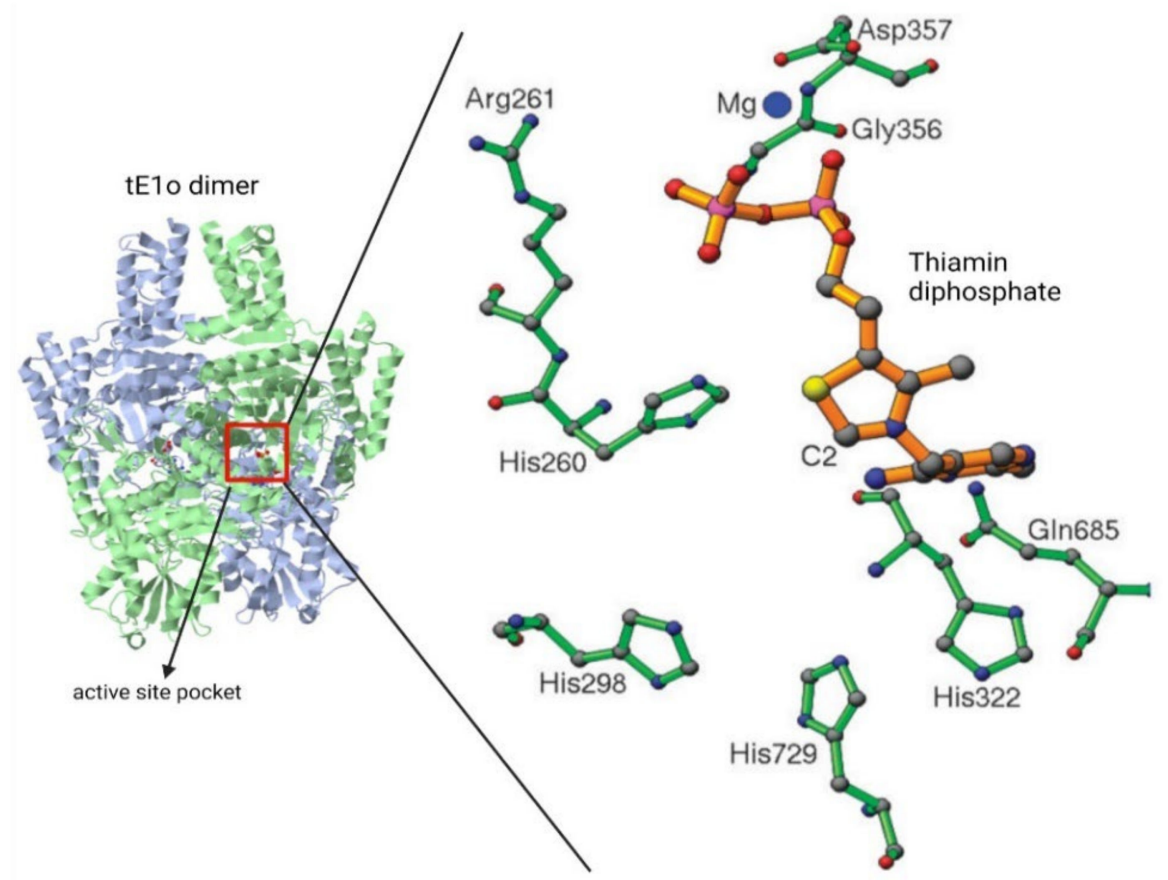

Figure 3. The E. coli E1o active site showing His260, His 298 and His 729 suggested to interact with the distal carboxylate of 2-OG (PDB: 2JGD) [39]. The ThDP coordinates were added by superimposing the X-ray coordinates for the E. coli E1o structure with that of the E. coli pyruvate dehydrogenase (E1p) [68].

The screening results revealed that His260 is a crucial residue for E1o function. Randomization at His260 yielded only one E1o variant (His260Glu) that could rescue the activity for 2-OG, albeit at a very low specific activity of $\sim 0.001 \%$ compared to wild-type E1o (Table 1). DNA sequencing identified several His298 E1o variants with the ability to decarboxylate 2-OG (His298Thr and His298Leu) as well as 2-OV (His298Asp and His 298 Val) (Table 1). Remarkably, the His298Asp substitution converted E. coli E1o to 2-oxovalerate dehydrogenase with an efficiency about 38-fold higher than that of wild-type E1o, while no activity was detected for this variant with 2-OG (Table 1) [68]. An important observation from these studies was that wild-type E1o could use both pyruvate and 2-OV as substrates; however, the NADH production could not be detected in the overall assay on assembly with E2o and E3 into OGDHc implying discrimination at the E2o level [68]. 
Table 1. Catalytic efficiencies of the E. coli E1o variants towards 2-OG and 2-OV [68].

\begin{tabular}{ccc}
\hline & \multicolumn{2}{c}{ DCPIP Activity $^{\mathbf{a}}$} \\
\cline { 2 - 3 } E1o Variant & $\begin{array}{c}\boldsymbol{k}_{\text {cat }} / \boldsymbol{K}_{m}, \mathbf{2 - O G} \\
\left(\mathbf{s}^{-\mathbf{1}} \mathbf{m} \mathbf{M}^{-\mathbf{1})}\right.\end{array}$ & $\begin{array}{c}\boldsymbol{k}_{\text {cat }} / \boldsymbol{K}_{\boldsymbol{m}}, \mathbf{2 - O V} \\
\left(\mathbf{s}^{-\mathbf{1}} \mathbf{~ m}^{-\mathbf{1})}\right.\end{array}$ \\
\hline Wild type & 824 & 0.0047 \\
His298Leu & 122 & 0.015 \\
His298Thr & 1.5 & 0.0020 \\
His298Asp & $\mathrm{Nd}$ & 0.18 \\
His298Val & 0.6 & 0.062 \\
His260Glu/His298Asn & 49.1 & $\mathrm{Nd}$ \\
His260Glu & 0.0084 & $\mathrm{Nd}$ \\
\hline
\end{tabular}

a Activity was measured in an E1-specific assay replacing the E2o and E3 components by an artificial electron acceptor, DCPIP. Nd, not detectable.

Next, the 2-oxophosphonate/2-oxophosphinate analogues of 2-OG and 2-OV (succinylphosphonate $\left(\mathrm{SP}^{2-}\right)$ and its monomethyl phosphonate ester $\left(\mathrm{SPME}^{-}\right)$, both analogues of 2-OG, and propionylphosphinate $\left(\mathrm{PP}^{-}\right)$, the phosphinate analogue of 2-oxovalerate (Figure 2, middle)) were tested for their ability to form the analogue of the pre-decarboxylation covalent intermediate with ThDP on E1o and its variants according to CD spectroscopic methods established in the Jordan laboratory [71,72]. This experiment would inform about stabilization of the pre-decarboxylation intermediate analogue, and inference of the true short-lived intermediate, in the E1o active centers (see Scheme 1, upper right-hand corner).

It was evident that the His260Asp E1o variant and His260/His298Asn E1o with dual substitution did not display any measurable circular dichroism (CD) band at $297 \mathrm{~nm}$ on titration by $\mathrm{SPME}^{-}$, the usual signature reflecting binding of the 2-oxophosphonate analogue. This experiment ${ }^{-}$provided strong evidence that His 260 is crucial and indispensable for 2-OG recognition in accord with the randomization experiment and kinetic studies [68]. In CD studies with the His298 E1o variants, the His 298Asp $\left(K_{d}, S P M E-=659 \mu \mathrm{M}\right)$, and His298Val $\left(K_{d}, S P M E-=144 \mu \mathrm{M}\right)$ substitutions were not favorable for $\mathrm{SPME}^{-}$binding, but the His298Tyr E1o $\left(K_{d, S P M E-}=6.1 \mu \mathrm{M}\right)$ could bind it successfully. However, all His298 substitutions were favorable for $\mathrm{PP}^{-}$binding, the phosphinate analogue of 2-OV $\left(K_{d, P P-}\right.$ in the 5.2-22.3 $\mu \mathrm{M}$ range). Furthermore, the His260Asp/His298Asn E1o dual substitution was favorable for $\mathrm{PP}^{-}$binding. With an average value of $K_{d, P P-}$ of $\sim 7.0 \mu \mathrm{M}$, the binding was approximately sixfold weaker compared to the wild-type E1o. The randomization at His298 E1o led to E1o variants being active toward 2-OG; however, the His298Asp and His298Val E1o variants yielded much better activity toward 2-OV [68].

In contrast to the E. coli E1o findings, the randomization at His281 in benzoylformate decarboxylase (BFDC) (the ThDP-dependent enzyme in the mandelate pathway which catalyzes the non-oxidative decarboxylation of benzoylformate to $\mathrm{CO}_{2}$ and benzaldehyde), led to variants with activities not very different from the wild-type enzyme. These results were inconsistent with earlier predictions by kinetic studies of the Ala-substituted BFDC variants $[18,73]$, suggesting that His281 could be the proton donor to the enamine intermediate. Those studies emphasized an important role of the SSM approach in helping interpret enzyme mechanisms, as Ala scanning solely is incapable of predicting the function of the residues [18]. A detailed summary of the application of SSM to other ThDP-dependent enzymes such as E. coli transketolase and 2-succinyl-5-enolpyruvyl- 6hydroxy-3-cyclohexene-1-carboxylate synthase (MenD) can be found in the review by Andrews and McLeish [18]. A major contribution of these SSM studies is not only to aid the understanding of mechanistic studies, but to also serve as guides in the search for novel asymmetric catalytic targets involving ThDP-dependent enzymes.

\section{E. coli E1o Catalyzes the Formation of Acetoin-like Products in a Carboligase Condensation Reaction}

The utility of ThDP-dependent enzymes in the asymmetric synthesis of $\alpha$-hydroxy ketones as precursors for fine chemicals in the pharmaceutical industry has been exten- 
sively studied and has been reviewed [22,71,74-81]. More recent applications of the ThDPdependent carboligases are found in biocatalytic cascade reactions, (or biocatalytic cascade strategy) $[82,83]$. Carboligation or C-C bond formation is a reaction catalyzed by a number of ThDP-dependent enzymes including transketolase from E. coli and Saccharomyces cerevisiae [84-86], acetohydroxy acid synthase (AHAS) [87-89], benzoylformate decarboxylase (BFDC) from Pseudomonas putida, benzaldehyde lyase (BAL) from Pseudomonas fluorescence [90-92], 2-succinyl-5-enolpyruvyl-6-hydroxy-3-cyclohexene- 1-carboxylate synthase (MenD) from E. coli $[75,93,94]$ among others. For some ThDP-dependent enzymes, carboligation is the principal reaction that has been used for the synthesis of chiral compounds with multiple functional groups in good yield and high enantiomeric excess. The carboligase reaction is one of the reactions emanating from the enamine intermediate (an intermediate present in all ThDP reactions), where the enamine reacts as a nucleophile towards mostly aldehyde and more seldomly ketone electrophiles. Carboligation is also a side-reaction for 2-oxo acid dehydrogenase complexes from both bacterial and mammalian sources (the efficiency is less than $1 \%$ compared to the physiological reactions). However, some active center variants of the yeast pyruvate decarboxylase (YPDC) and the E1p component of the E. coli PDHc prefer a carboligation pathway producing acetoin (3-hydroxy-2-butanone) and acetolactate rather than the physiological product $[71,95,96]$. Acetoin is the major product formed when pyruvate and acetaldehyde are used as substrates with YPDC $((R)$-acetoin) and PDHc-E1 variants ((S)-acetoin) (see Scheme 2 for carboligation reaction). Acetolactate is the product formed when pyruvate is used as the sole substrate for YPDC ((S)-acetolactate) and for E. coli E1o ((R)-acetolactate) (Scheme 2$)$. It is evident that the two enzymes form enantiomers with different stereochemical outcomes.

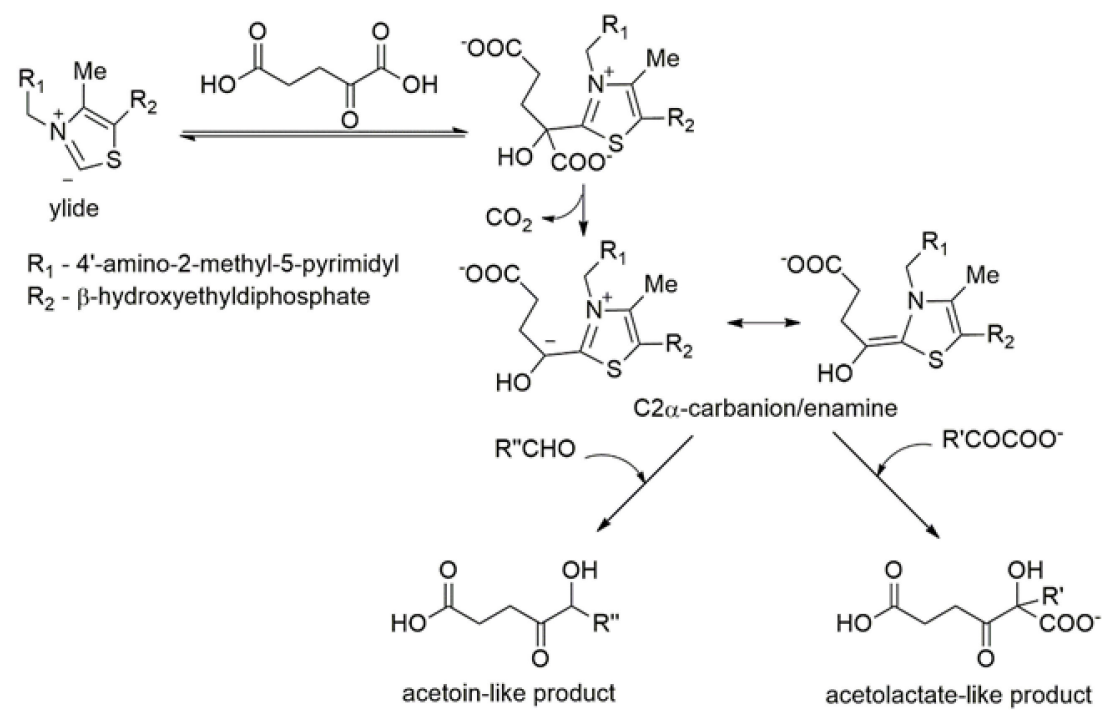

Carboligation products

Scheme 2. Mechanism of the carboligase side reaction forming acetoin and acetolactate suggested for YPDC and for E. coli pyruvate dehydrogenase [71].

The E. coli E1o, catalyzes the initial formation of the ThDP-bound post-decarboxylation intermediate ( $\mathrm{C} 2 \alpha$-carbanion/enamine) from 2-OG which is reactive towards electrophilic acceptor substrates, such as aromatic substrates and aliphatic aldehydes with different chain lengths but with moderate to excellent enantioselectivity [75]. In our laboratories the carboligation reaction of E. coli E1o was studied by using the natural substrate 2-OG as well as the non-natural substrates 2-OV and 3-methyl 2-oxobutanoic acid (2-OiV) (Table 2) with no second charge in the 2-oxo acid: one of them with a straight chain (2-OV) and the other with a branched one (2-OiV) [97]. Three aldehyde acceptors, glyoxylate, ethyl glyoxylate and methylglyoxal, were successfully employed with these donor substrates that lead to a variety of chiral products according to $\mathrm{CD}$ and ${ }^{1} \mathrm{H}$ NMR spectra and lead to 
products in good yield with up to $80-90 \%$ enantiomeric excess according to chiral gas chromatography (Table 2) [97]. It was evident that the acetoin-like products displayed different stereospecificities depending on the donor substrates and acceptors employed in the E. coli E1o reaction. Thus, with 2-OG as a substrate and glyoxylate or ethylglyoxylate as acceptors, the $(R)$-2-hydroxy-3-oxohexanedioic acid and $(R)$-6-ethoxy-5-hydroxy-4,6-dioxohexanoic acid were formed (Figure 4, panel A). However, when methylglyoxal was used as an acceptor, the (S)- -5-hydroxy-4,6-dioxoheptanoic acid was produced (Figure 4, panel A). When 2-OV was used as a substrate and glyoxylate or ethylglyoxylate as acceptors, the E. coli E1o produced (S)-enantiomers (Table 2). Furthermore, with 2-OiV as a substrate and employing either glyoxylate or ethylglyoxylate or methylglyoxal as an acceptor, E. coli E1o produced the $(S)$ enantiomers. The scope of the E. coli E1o carboligation reaction was extended by our groups to the synthesis of chiral carboligation products with multiple functional groups by employing varying substrates, such as 2-oxoadipate (2-OA), 2-oxohexanoic acid and 2-oxo-5-hexenoic acid, which are structurally similar to the carboxylic acids (Figure 2, top) and the straight chain aldehydes as acceptors (Figure 2, bottom) [69]. Formation of chiral products on an analytical scale by E. coli E1o was confirmed by recording the CD spectra of the products formed and by ${ }^{1} \mathrm{H}$ NMR spectroscopy (see Figure 4, panels A, B for chiral products identified) [69].

Table 2. Acetoin-like products formed by E. coli E1o (yield for all products was determined by ${ }^{1} \mathrm{H}$ NMR with no starting material detected) [97].

\begin{tabular}{cccc}
\hline Substrates & Acceptors & Product & $\begin{array}{c}\text { Enantiomeric } \\
\text { Excess }\end{array}$ \\
\hline 2-OG & Glyoxylate & 1 & $90 \%(R)$ \\
2-OV & 2 & $96 \%(S)$ \\
2-OiV & 3 & $67 \%(S)$ \\
\hline 2-OG & & 4 & $81 \%(R)$ \\
2-OV & Ethyl-glyoxylate & 5 & $52 \%(S)$ \\
2-OiV & 6 & $81 \%(S)$ \\
\hline 2-OG & & 7 & $83 \%(S)$ \\
2-OV & & 8 & $81 \%(R)$ \\
2-OiV & Methyl-glyoxal & 9 & $>90 \%(S)$ \\
\hline
\end{tabular}

More recently, the studies were also extended at Rutgers to a carboligation-type synthesis using human E1o from 2-OG and from 2-OA [63,98]. With 2-OG as a substrate donor and glyoxylate as an acceptor, $(R)$-2-hydroxy-3-oxohexanedioic acid $((R)$-2-hydroxy3-oxoadipate) (Figure 4, panel A) was detected in the CD experiments with an estimated catalytic efficiency $\left(k_{\text {cat }} / K_{m, O G}\right)$ of about $4.8 \%$ compared to the E1o-specific activity (Figure 4, panel B). With 2-OA as a substrate and glyoxylate as an acceptor substrate, (S)-2hydroxy-3-oxoheptanedioic acid (2-hydroxy-3-oxopimelic acid) could be detected (Figure 4, panel B). It is notable that, while 2-OA could serve as a substrate for human OGDHc, the human E1o efficiency toward 2-OA $\left(k_{c a t} / K_{m, O A}\right)$ is about 18-19-fold lower compared to that for 2-OG in both the overall and E1-specific assay [63]. With regard to the carboligation reaction, the human 2-oxoadipate dehydrogenase (human E1a, also known as DHTKD1) in the L-lysine degradation pathway is the most promiscuous enzyme, which could successfully decarboxylate substrates with 5 (2-OG), 6 (2-OA) and 7 (2-oxopimelic acid) carbon atoms $[63,65]$. By analogy with the carboligation reaction of human E1o, it produced $(R)$-2-hydroxy-3-oxoadipate in the 2-OG: glyoxylate carboligation reaction and (S)-2-hydroxy-3-oxoheptanedioic acid in the 2-OA: glyoxylate carboligation reaction, similar predominant enantiomers as produced by human E1o. Formation of the carboligation products by human E1a represents a potential value for chemoenzymatic synthesis. Considering the broad substrate specificity of the human E1a component, it could be effectively employed in the chemoenzymatic synthesis of chiral $\alpha$-hydroxy ketones, valuable synthetic intermediates. These findings expand the scope of both substrate donors and 
aldehyde acceptors to be employed in carboligation reactions. Different enantioselectivities in product formation could be achieved by using three enzymes: the E. coli and human E1o and human E1a.

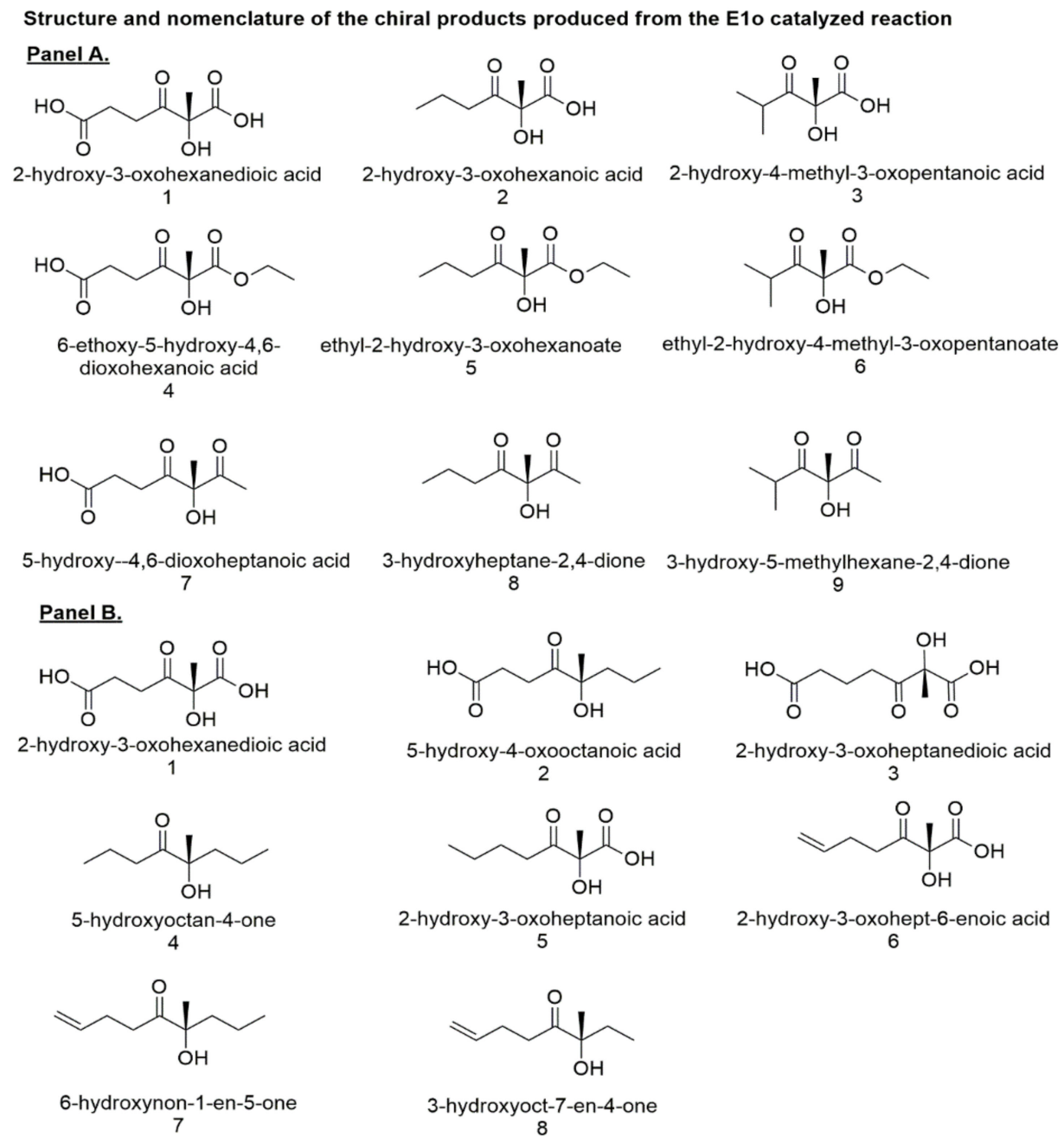

Figure 4. Structure of the chiral products formed by E. coli E1o in carboligation reaction by using different acceptors and substrates in Figure 2 (top and bottom) $[69,97]$. The formation of products 1 and 3 by using 2-OG and 2-OA as substrates and glyoxylate as an acceptor was also demonstrated for the human E1o [63,64,69]. Panel A represent all chiral products corresponding to Table 2. Panel B represent chiral products using carboxylic acids which are structurally similar to 2-oxo acids (2-oxoadipic acid, 2-ketohexanoic acid and 2-oxo-5-hexenoic acid) and acceptors (glyoxalate, butyraldehyde and propanal).

\section{Site-Saturation Mutagenesis Studies Clarified Catalysis of the Transthioesterification Reaction on the E. coli E2o and Corrected a Long-Misunderstood Mechanism Relevant to All E2 Components}

The engineering of the E. coli E2o had two objectives: (a) to understand the catalytic mechanism of the E. coli E2o core domain and (b) to assign a role to the key residues in the mechanism. It needs to be noted that after years of multiple structural studies on the E2 catalytic domain by X-ray $[46,99,100]$ and by cryo-EM [52-54,59,101,102], the catalytic mechanism of the E2 component remains elusive. Earlier, based on a comparison of the primary sequences and predicted secondary structures of the E2 enzymes with that of chloramphenicol acetyltransferase (CAT), the mechanism proposed for E2 [103] included an active site histidine as a general-base catalyst responsible for the deprotonation of the reactive thiol of CoA, analogously to that proposed for the active site His195 in CAT [104]. 
The CAT and the subtilisin family of serine proteases are considered as gold standards for acid-base catalysis [105]. It was predicted that E2o [99] belongs to the same class of enzymes, with the catalytic His having a similar proton-donor/acceptor role in the acyltransfer reaction [99]. Understanding the role of His375 in E. coli E2o was pivotal to gain insight into the catalytic mechanism of the acyl transfer reaction for production of acylCoA derivatives. Furthermore, with the increasing resolution of the cryo-EM structures of the E2 core domains and an attempt to understand the molecular mechanism of substrate channeling by the lipoyl domains [52], an understanding of the E2o catalytic mechanism becomes critical.

The X-ray structure of the E. coli E2o catalytic/core domain had been reported earlier (Figure 5A) [66,99]. Briefly, the E. coli E2o core domain assembles into a 24-subunit oligomer where tightly associated trimers are arranged at the corners of the cube [99]. The substratebinding channel is $\sim 30 \AA$ long, and it is formed by the interaction between two of the threefold related subunits. One side of the channel in the E. coli E2o core domain is exposed to solvent [99]. The catalytic residues His375 from one subunit and Thr323 from another subunit are positioned in the middle of the channel [99]. In our studies, the single-site substitution at the highly conserved His 375 , Asp374 and Thr323 from the E. coli E2o active center revealed that His375 and Asp374 but not Thr323 are catalytically the most important residues for succinyl transfer in both the physiological and reverse directions (see Figure 5B for steady-state kinetic data) [106]. The calculated value of the rate retardation resulting from the His375Ala substitution in E. coli E2o of 54-fold (this number represents the ratio of $\left(k_{\text {cat }} / K_{m}\right)_{\text {wild-type }} /\left(k_{\text {cat }} / K_{m}\right)_{\text {variant }}$ in Figure $\left.5 \mathrm{~B}\right)$ was much smaller compared to the $\sim 500,000$ value calculated for His195Ala CAT, suggesting different functions for the highly conserved active center histidine on the two enzymes. More insight into the possible role of His375 came from SSM studies, in which the His375Trp E2o variant displayed a significant retention of the overall NADH activity $(\sim 60 \%)$ and showed similar $\mathrm{pH}$ dependence of the NADH activity, as well as similar binding ability for CoA and for succinyl-CoA, in comparison with unsubstituted E2o [106].

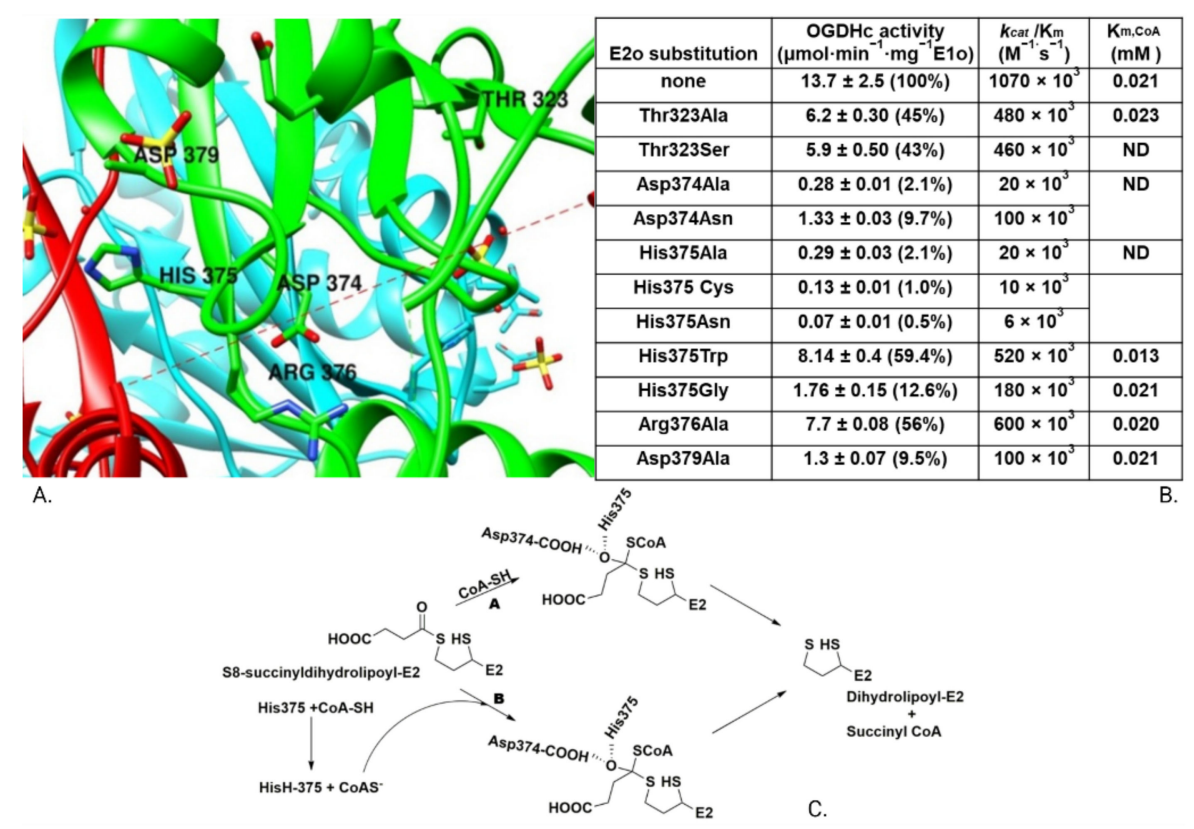

Figure 5. The active center of the E. coli E2o and suggested catalytic mechanism. (A) The E2o active center is located between the threefold related subunits shown in red, green and blue. The E2o active center residues of Thr323, Asp374, His375, Arg376 and Asp379 are indicated. (B) The effect of substitutions in the E2o active center on the catalytic efficiency of the OGDHc. (C) Two mechanisms suggested in pathways (A) and (B) for succinyl transfer from dihydrolipoamide-E2o to CoASH [106]. Created with Biorender.com. 
Although it is unclear why an aromatic ring substitution is tolerated at the active site histidine in multiple instances, it is safe to speculate that a possible steric effect of this histidine imidazole is to ensure intermediate tunneling through the active site [106]. Altogether, these findings question the general base role assigned to the conserved catalytic histidine of the acyl transferase class of enzymes. Two plausible mechanisms could be suggested for the transfer of an acyl group between two thiols by E. coli E2o. Lower pathway is a general acid-base mechanism, were the His375 converts the thiol of the attacking nucleophile (CoASH) to a thiolate anion $\left(\mathrm{CoAS}^{-}\right)$(Figure 5C, pathway B). The activated thiolate then attacks the carbonyl atom of succinyldihydrolipoyl-E2o to form a tetrahedral intermediate, which is stabilized by a hydroxyl side chain of Thr323 in accord with a mechanism suggested for CAT [103,104,107]. In the upper pathway, as an alternative to the acid-base catalysis mechanism, a direct attack by a thiolate anion (pKa $\sim 7.0$ for the SHgroup) on the thiol ester carbon of the S8-succinyldihydrolipoyl-E2o was suggested with the formation of a symmetrical tetrahedral oxyanionic intermediate, where the central carbon atom is flanked by two C-S bonds with a near equal probability for cleavage (Figure 5 C, pathway A) [106]. The His375 and Asp374 residues in E. coli E2o are more likely involved in the stabilization of the oxyanionic intermediate by two hydrogen bonds. The His374Asn substitution in E. coli E2o (0.5\% remaining activity) led to a further reduction in the OGDHc catalytic efficiency by $\sim$ fourfold compared to the His375Ala substitution $(2.1 \%$ remaining activity) (Figure 5B). In contrast, the Asp374Gln substitution rescued the E2o activity (9.7\%) compared to the Asp374Ala substitution (2.1\%), suggesting that Asp374 is involved in hydrogen bond formation. Additionally, according to SSM studies, the His375Trp E2o substitution led to an OGDHc activity of about $60 \%$ compared to wild-type E2o, arguing strongly against the acid-base role of His375 [106]. This conclusion is consistent with data reported earlier from McLeish's group on the ThDP-dependent enzyme BFDC, where SSM studies on the active site His281 led to His281Phe and His281Trp variants with significant remaining activity compared to the wild-type enzyme, also arguing against an acid-base role for His281 [18]. In addition to elucidating this long-misunderstood mechanism of the transthioesterification reaction carried out by E. coli E2o, the findings are most likely applicable to all E2 enzymes and provide crucial information for further engineering of the E. coli E2o for producing a variety of acyl-CoA analogues.

A further important aspect of OGDHc assembly was revealed when recombinant E2o domains (LD and CD) were individually expressed, purified and mixed with E1o and E3 to assemble OGDHc in vitro. The complex, so assembled, displayed overall activity with 2-OG, leading to the conclusion that covalent bonding between the domains is not required for OGDH-complex assembly and activity.

\section{Expansion of E2o Substrate Specificity and Creation of the 2-oxo Aliphatic Acid Dehydrogenase Complex with Goals of Acyl CoA Analogue Synthesis}

Engineering of the E. coli E1o by single amino acid substitution led to changing its substrate specificity [68]. Thus, the His298Asp and His298Val substitutions converted the E. coli E1o to 2-oxovalerate dehydrogenase with activities comparable to those observed with 2-OG. However, when E1o variants were assembled with E2o and E3 into OGDHc, no NADH formation was detected with 2-OV as a substrate, implying discrimination at the E2o level [68]. In view of these findings, the E. coli E2o catalytic domain was next engineered to accept substrates other than succinyllysyldihydrolipoamide. Earlier, based on the alignments of known E2o, E2p and E2b enzymes, it was suggested that Gly325, Ser333 and Arg381 might contribute to the substrate specificity of the E. coli E2o core [108,109]. In the absence of the E2o core domain structure with succinyllysyldihydrolipoamide bound, the residues that may be implicated in substrate binding were identified based on molecular modeling studies [99]. According to those model studies, the carboxyl group of the $S$-succinyllysyldihydrolipoamide forms hydrogen bonds with the hydroxyl groups of Ser330 and/or Ser333 [99]. The His348, conserved among known E2o sequences, is located 
near the proposed succinyl-binding site and was predicted to be responsible for recognition of the succinyl group (Figure 6) [66,99].

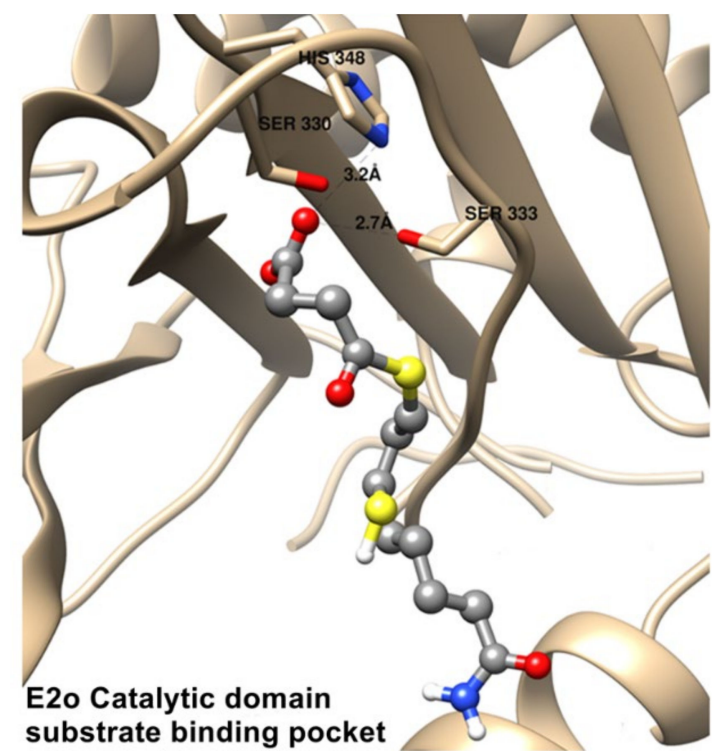

Figure 6. The succinyl-binding site of the E. coli E2o catalytic domain with succinyldihydrolipoamide modeled into it [110]. The succinyl-binding site contains residues Ser330 and Ser333 within hydrogenbonding distance of the carboxylate group of succinyldihydrolipoamide. The His 348 which may be responsible for substrate recognition is shown. The modeling was performed by using UCSF Chimera Autodock program [111] and coordinates of the E. coli E2o catalytic domain deposited under the accession number 1C4T [99].

In the Farinas lab, SSM libraries were constructed for the E. coli E2o at positions Ser330, Ser333 and His348 were constructed [110]. The E2o variants with the His348Phe, His348Tyr, His348Gln and Ser333Met substitutions were identified from the screen. On reconstitution of the purified E2o proteins with substitutions identified with His298Asp-E1o and E3 into OGDHc, the formation of NADH from 2-OV could be detected in vitro (Table 3). Moreover, the formation of butyryl-CoA by the newly designed complexes could be detected by mass spectrometry [110]. Surprisingly, the identified His348 E2o variants retained the OGDHc activity toward the natural substrate 2-OG with the maximum reduction of catalytic efficiency $\left(k_{\text {cat }} / K_{m, 2-O G}\right)$ by only 1.6 -fold (His348Gln E2o). The E2o variants were also found to be active towards an even more hydrophobic substrate, 2-oxo-5-hexenoic acid (2-OHe), which contains a terminal alkene group that would be useful for further functionalization to increase product diversity (Figure 2, top) [110]. It needs to be noted that when assembled from unsubstituted E1o, E2o and E3 components, no NADH could be detected for OGDHc with $2-\mathrm{OV}$ or $2-\mathrm{OHe}$ as substrates. Related to residue His348, proposed to interact with the distal carboxylate of $S$-succinyllysyldihydrolipoamide [99], the OGDHc assembled with the His348Phe or His348Tyr E2o variants displayed higher activity compared to the His348Gln E2o variant with both $2-\mathrm{OV}$ and $2-\mathrm{OHe}$ as substrates. One might simply attribute this to the presence of a hydrophobic amino acid in that position being favorable to recognize the butyryl group of the substrate. Modeling the solvent-accessible volume for the binding channel revealed that phenylalanine and tyrosine substitutions at His348 do not alter the solvent-accessible volume, thus providing a higher catalytic efficiency versus 2-OV and 2-OHe (Table 3). With His348Gln E2o, where the histidine and glutamine have a similar size, the glutamine substitution creates a smaller solvent-accessible volume compared to unsubstituted E2o, leading to a lower catalytic efficiency versus 2-OG, 2-OV and 2-OHe (Table 3) [110]. The Ser333Met E2o substitution led to only a threefold-lower catalytic efficiency of the OGDHc with 2-OG compared to wild-type E2o and retained the highest activity with 2-OHe among the other E2o variants (Table 3). The Met or Gln substitutions 
led to a decrease in the pocket volume, which possibly leads to unfavorable interactions with 2-OG. However, such an environment was favored for 2-OHe to be the substrate of choice. Thus, this study elucidates another aspect of the reactivity, where the importance of the microenvironment in the active site channel is extremely important and affects substrate recognition in E. coli OGDHc. Furthermore, the changes in the active site channel would be otherwise impossible to predict other than from extensive kinetic studies.

Table 3. Catalytic efficiency of the OGDH complexes assembled with E2o variants ${ }^{\text {a }}$ [110].

\begin{tabular}{|c|c|c|c|}
\hline E2o Substitution & $\begin{array}{c}k_{c a t} / K_{m}, 2-\mathrm{OG} \\
\left(\mathrm{s}^{-1} \mathrm{mM}^{-1}\right)\end{array}$ & $\begin{array}{c}k_{c a t} / K_{m}, 2-\mathrm{OV} \\
\left(\mathrm{s}^{-1} \mathrm{mM}^{-1}\right)\end{array}$ & $\begin{array}{c}k_{c a t} / K_{m}, 2-\mathrm{OHe} \\
\left(\mathrm{s}^{-1} \mathrm{mM}^{-1}\right)\end{array}$ \\
\hline None ${ }^{b}$ & 875 & No activity & No Activity \\
\hline None $^{\mathrm{c}}$ & 703 & No activity & No activity \\
\hline His348Phe ${ }^{\mathrm{d}}$ & 244 & 81 & 1.98 \\
\hline His348Gln ${ }^{d}$ & 149 & 6.8 & 0.59 \\
\hline His348Tyr d & 338 & 57 & 1.17 \\
\hline Ser333Met ${ }^{d}$ & 210 & 4.7 & 15.3 \\
\hline \multicolumn{4}{|c|}{$\begin{array}{l}\text { a The overall OGDHc activity was detected in vitro by formation of NADH. }{ }^{b} \text { The OGDHc was assembled from } \\
\text { unsubstituted E1o, E2o and E3 components. }{ }^{c} \text { The OGDHc was assembled from His298Asp-E1o, wild-type E2o } \\
\text { and E3. }{ }^{d} \text { The OGDHc was assembled from His298Asp-E1o, E2ovariant and E3. Finally, the E. coli OGDHc is the } \\
\text { first example of the 2-oxo acid dehydrogenase complexes which was evolved from a 2-oxo acid dehydrogenase } \\
\text { complex to a 2-oxo aliphatic acid dehydrogenase complex by engineering the two consecutive E1o and E2o } \\
\text { components on the pathway. }\end{array}$} \\
\hline
\end{tabular}

\section{Conclusions and Perspectives}

The major focus of the current review was to explore the power of protein engineering methods to investigate active site catalysis and further expansion of the substrate range of multienzyme complexes. This was done in view of the strategies implemented for evolution of the rudimentary case study of OGDHc. Notably, modern day enzymes have evolved by recruiting primitive singular enzymes performing sequential, divergent or convergent chemical reactions. Furthermore, under selection pressure, the complexes have achieved exquisite substrate-channeling efficiencies. This is extremely difficult to mimic inside a laboratory using traditional scaffolding/colocalization approaches [23-25]. Further, to broaden the substrate range of the entire complex, engineering is required at each component level, followed by assembly of the overall complex. Thus, a thorough understanding of both substrate binding and catalysis is essential in order to implement the complex for chemoenzymatic synthetic purposes. Although recent advances in machine learning and artificial intelligence can accurately predict protein structures from an evolutionary database, the actual protein-protein interactions and structure-function relationships baffle scientists. A notable example in this aspect has been demonstrated by the use of AlphaFold, an artificial-intelligence-based rapid theoretical protein prediction program [112]. The method appears remarkable in its predictive power for the structure of monomeric proteins. For the present, however, the prediction of interactions among different components in a multienzyme complex, consisting of multiple copies of each of three components, such as the 2-OGDHc, is still on hold for the near future [26]. For such multimeric assembly ( 4-5 MDa) enzyme complexes, the pieces of the puzzle can be put together mainly by mutagenesis (directed or site saturation) approaches. Only then can the overall complex characterization be expressed as a summation of catalysis and substrate binding/specificities at individual component levels. This knowledge is the fundamental stepping stone of the engineering process to further move forward with its broad chemoenzymatic synthetic goals.

Over the years, the pharmaceutical, food, detergent and biofuel industries have reaped the advantages of enzyme catalysis on industrial scale applications. In cases of complex chemical reactions, the most significant advantages of biological (enzyme) catalysts 
include high stereo-, chemo- and regioselectivities [113]. The pharmaceutical industry has successfully exploited engineered-enzyme-mediated catalysis to synthesize complex compounds that are difficult to synthesize by traditional chemical catalysis. A notable example is the drug sitagliptin, marketed by Merck for type II diabetes treatment [114-116]. Acyl-CoA and its analogs are considered important intermediates in organic chemistry and drug development pipelines. Traditional organic synthetic pathways for the acylation of thiols or transthioesterification involve the use of acyl sources from carboxylic acids, acid anhydrides or acid chlorides. The reactions proceed in the presence of strong bases such as ethylamine, pyridine or DMAP for refluxing for several hours. In short, these are multistep chemical reactions, energy intensive and involving extreme reaction conditions, which can be hazardous to the environment [117]. Incidentally, the final product of the main transthioesterification reaction catalyzed by OGDHc is a CoA-linked thioester (succinylCoA). Further, the side-reaction of the E1o component is carboligation, which is also of immense importance in the chemistry world for the synthesis of chiral carbon compounds. This makes OGDHc a suitable candidate for one-pot multistep green chemical synthesis under much milder aqueous conditions, thus providing a sustainable and green synthetic chemical pathway.

OGDHc is a well-evolved multienzyme complex of a conserved metabolic pathway across many different species. Site saturation mutagenesis in the active sites of E1o and E2o effectively assigned roles to the pivotal residues contributing to catalysis. It is important to recognize that such assignments using structural homology modelling would be difficult to predict. The principal achievements in this approach that differentiate between our research and work by others are summarized below.

(a) The E1o component of the E. coli OGDHc was engineered to accept substrates lacking the 5-carboxylate group by subjecting His260 and His298 in the active center to site saturation mutagenesis. The results rule out an acid-base or hydrogen-bonding role for His298; however, they confirmed a hydrogen-bonding role for His260. It was suggested that the E2o component is a 'gatekeeper' for 2-OG channeling through the pathway.

(b) It was demonstrated that the E. coli E1o can accept 2-oxovalerate and 2-oxoisovalerate in addition to its natural substrate 2-oxoglutarate in the carboligation reaction and that glyoxylate, ethyl glyoxylate and methylglyoxal can serve as aldehyde acceptors, producing acetoin-like compounds with good enantioselectivity. The novel products formed by the carboligation reaction include chiral 2-hydroxy-1,3-diketones and 2 -hydroxy- $\beta$-ketoesters. The E. coli E1o offers a good starting point for protein engineering and optimization to synthesize stable chiral intermediates for fine chemical synthesis.

(c) The fundamental mechanism of the transthioesterification reaction carried out by the E2o component of the E. coli OGDHc was elucidated, leading to the identification of Asp374 and His375 residues in the E2o catalytic center that are important for succinyl transfer in both the physiological and the reverse directions. The evidence provided ruled out a role of acid-base catalysis by His375. It was suggested that His375 and Asp 374 are involved in the stabilization of the tetrahedral oxyanionic intermediate through hydrogen bond donation. It was concluded that a rate-limiting step on E. coli OGDHc is succinyl transfer to $\mathrm{CoA}$, thus providing crucial information for producing a variety of acyl-CoA analogues.

(d) 6.4. The engineering of two consecutive components, E1o and E2o, was accomplished. The promiscuous variant components assembled into OGDHc were able to catalyze reactions with both natural and unnatural substrates, leaving significant room for optimization. Similar to natural evolution, the new pathway could be engineered to suit particular user-defined goals. These designed routes can function together with the existing pathways and could be utilized for chemical and synthetic purposes [118].

Cellular organization and function have evolved over millions of years under natural selection pressure. The 2-oxoacid-dehydrogenase complexes are the molecular machinery 
that have been fine tuned to carry out cellular reactions with maximum efficiency. Catalytic promiscuity has been the likely driving force for development of specialized enzymes such as human E1a (2-oxoadipate-dependent component), catalyzing novel reactions compared to human E1o [119]. Furthermore, the approach to evolve a multienzyme complex takes into consideration the recruitment of sequential enzymes into self-assembled multicomponent supramolecular structures and performance of multistep metabolic reactions effortlessly. The knowledge of this organization by recent cryo-EM studies is a major effort that would provide molecular biologists with a platform from which structure-function relationships can be probed and fabricated towards user-defined interests [120,121]. Future extensions of the SSM methods here explored could focus on the demonstrated promiscuity of the (a) Human E1a component of a multienzyme complex related to OGDHc in the L-lysine degradation pathway, as it accepts, in addition to 2-oxoadipate, 2-oxoglutarate and 2oxopimelate as substrates, all capable of participating in ThDP-dependent carboligation reactions as 'acceptor' partners to produce novel chiral $\alpha$-hydroxyketones; and (b) Human E2o active center with its ability to synthesize, in addition to its physiological product succinyl-CoA, glutaryl-CoA and adipoyl-CoA.

In the next step, directed evolution strategies could be implemented to improve the new catalytic activities and yield of products $[122,123]$. Traditionally, metabolic pathways are not considered fertile grounds for biocatalyst development [124]. However, the potential of the development of orthogonal novel pathways from existing metabolic pathways could be an exciting avenue in the world of green synthesis. In the post-genomic era and, with the help of protein engineering, the potential utility of such complexes to a chemist is invaluable.

Author Contributions: Conceptualization, J.C., E.T.F. and F.J; writing—original draft preparation, J.C., N.N., E.T.F. and F.J.; writing-review and editing, J.C., N.N., Y.S., X.Z., E.L.G., H.P., E.T.F. and F.J.; visualization, J.C., N.N.; supervision, E.T.F. and F.J.; project administration, E.T.F. and F.J.; funding acquisition, E.T.F. and F.J. All authors have read and agreed to the published version of the manuscript.

Funding: We are grateful for financial support from the National Science Foundation (1402675 [F.J.], 1402729 [E.T.F.]), National Institutes of Health (R15 GM116077 [F.J.]) and Chancellor's Seed Grant (Rutgers University; to F.J.).

Conflicts of Interest: The authors declare no conflict of interest with the work reviewed.

\section{References}

1. Hammer, S.C.; Knight, A.M.; Arnold, F.H. Design and evolution of enzymes for non-natural chemistry. Curr. Opin. Green Sustain. Chem. 2017, 7, 23-30. [CrossRef]

2. Tracewell, C.A.; Arnold, F.H. Directed enzyme evolution: Climbing fitness peaks one amino acid at a time. Curr. Opin. Chem. Biol. 2009, 13, 3-9. [CrossRef] [PubMed]

3. Carter, P.; Nilsson, B.; Burnier, J.P.; Burdick, D.; Wells, J.A. Engineering subtilisin BPN' for site-specific proteolysis. Proteins Struct. Funct. Genet. 1989, 6, 240-248. [CrossRef] [PubMed]

4. Nigel, S.; Berry, A.; Perham, R. Redesing of the coenzyme specificity of a dehygrogenase by protein engineering. Nature 1990, 343, 38-43.

5. Dalby, P.A. Optimising enzyme function by directed evolution. Curr. Opin. Struct. Biol. 2003, 13, 500-505. [CrossRef]

6. Park, S.; Morley, K.L.; Horsman, G.P.; Holmquist, M.; Hult, K.; Kazlauskas, R.J. Focusing Mutations into the P. fluorescens Esterase Binding Site Increases Enantioselectivity More Effectively than Distant Mutations. Chem. Biol. 2005, 12, 45-54. [CrossRef] [PubMed]

7. Strausberg, S.L.; Ruan, B.; Fisher, K.E.; Alexander, P.A.; Bryan, P.N. Directed Coevolution of Stability and Catalytic Activity in Calcium-free Subtilisin. Biochemistry 2005, 44, 3272-3279. [CrossRef]

8. Morley, K.L.; Kazlauskas, R.J. Improving enzyme properties: When are closer mutations better? Trends Biotechnol. 2005, 23, 231-237. [CrossRef]

9. Chica, R.A.; Doucet, N.; Pelletier, J.N. Semi-rational approaches to engineering enzyme activity: Combining the benefits of directed evolution and rational design. Curr. Opin. Biotechnol. 2005, 16, 378-384. [CrossRef]

10. Arnold, F.H.; Georgiou, G. Directed Enzyme Evolution: Screening and Selection Methods; Humana Press: Totowa, NJ, USA, 2003; 383p.

11. Gupta, N.; Farinas, E.T. Directed evolution of CotA laccase for increased substrate specificity using Bacillus subtilis spores. Protein. Eng. Des. Sel. 2010, 23, 679-682. [CrossRef] 
12. Gupta, N.; Farinas, E.T. Narrowing laccase substrate specificity using active site saturation mutagenesis. Comb. Chem. High. Throughput Screen. 2009, 12, 269-274. [CrossRef] [PubMed]

13. Glieder, A.; Farinas, E.T.; Arnold, F.H. Laboratory evolution of a soluble, self-sufficient, highly active alkane hydroxylase. Nat. Biotechnol. 2002, 20, 1135-1139. [CrossRef] [PubMed]

14. Chen, K.; Arnold, F.H. Tuning the activity of an enzyme for unusual environments: Sequential random mutagenesis of subtilisin E for catalysis in dimethylformamide. Proc. Natl. Acad. Sci. USA 1993, 90, 5618-5622. [CrossRef] [PubMed]

15. Arnold, F.H. Protein engineering for unusual environments. Curr. Opin. Biotechnol. 1993, 4, 450-455. [CrossRef]

16. You, L.; Arnold, F.H. Directed evolution of subtilisin E in Bacillus subtilis to enhance total activity in aqueous dimethylformamide. Protein. Eng. Des. Sel. 1996, 9, 77-83. [CrossRef]

17. Kan, S.B.J.; Lewis, R.D.; Chen, K.; Arnold, F.H. Directed evolution of cytochrome c for carbon-silicon bond formation: Bringing silicon to life. Science 2014, 522, 1048-1051. [CrossRef]

18. Andrews, F.H.; McLeish, M.J. Using site-saturation mutagenesis to explore mechanism and substrate specificity in thiamin diphosphate-dependent enzymes. FEBS J. 2013, 280, 6395-6411. [CrossRef]

19. Zhou, C.; Saravanan, T.; Lorillière, M.; Wei, D.; Charmantray, F.; Hecquet, L.; Fessner, W.; Yi, D. Second-Generation Engineering of a Thermostable Transketolase (TKGst) for Aliphatic Aldehyde Acceptors with Either Improved or Reversed Stereoselectivity. ChemBioChem. 2017, 18, 455-459. [CrossRef]

20. Yu, H.; Yan, Y.; Zhang, C.; Dalby, P.A. Two strategies to engineer flexible loops for improved enzyme thermostability. Sci. Rep. 2017, 7, 41212. [CrossRef]

21. Morris, P.; García-Arrazola, R.; Rios-Solis, L.; Dalby, P.A. Biophysical characterization of the inactivation of E. coli transketolase by aqueous co-solvents. Sci. Rep. 2021, 11, 23584. [CrossRef]

22. Müller, M.; Sprenger, G.A.; Pohl, M. CC bond formation using ThDP-dependent lyases. Curr. Opin. Chem. Biol. 2013, 17, 261-270. [CrossRef] [PubMed]

23. Ricca, E.; Brucher, B.; Schrittwieser, J.H. Multi-Enzymatic Cascade Reactions: Overview and Perspectives. Adv. Synth. Catal. 2011, 353, 2239-2262. [CrossRef]

24. Schrittwieser, J.H.; Velikogne, S.; Hall, M.; Kroutil, W. Artificial Biocatalytic Linear Cascades for Preparation of Organic Molecules. Chem. Rev. Am. Chem. Soc. 2018, 118, 270-348. [CrossRef] [PubMed]

25. García-Junceda, E.; Lavandera, I.; Rother, D.; Schrittwieser, J.H. (Chemo)enzymatic cascades-Nature's synthetic strategy transferred to the laboratory. J. Mol. Catal. B Enzym. 2015, 114, 1-6. [CrossRef]

26. Bugada, L.F.; Smith, M.R.; Wen, F. Engineering Spatially Organized Multienzyme Assemblies for Complex Chemical Transformation. ACS Catal. 2018, 8, 7898-7906. [CrossRef]

27. Wilner, O.I.; Weizmann, Y.; Gill, R.; Lioubashevski, O.; Freeman, R.; Willner, I. Enzyme cascades activated on topologically programmed DNA scaffolds. Nat. Nanotechnol. 2009, 4, 249-254. [CrossRef]

28. Dueber, J.E.; Wu, G.C.; Malmirchegini, G.R.; Moon, T.S.; Petzold, C.J.; Ullal, A.V.; Prather, K.L.J.; Keasling, J.D. Synthetic protein scaffolds provide modular control over metabolic flux. Nat. Biotechnol. 2009, 27, 753-759. [CrossRef] [PubMed]

29. Grotzky, A.; Nauser, T.; Erdogan, H.; Schlüter, A.D.; Walde, P. A fluorescently labeled dendronized polymer-enzyme conjugate carrying multiple copies of two different types of active enzymes. J. Am. Chem. Soc. 2012, 134, 11392-11395. [CrossRef]

30. Chen, S.; Wen, L.; Svec, F.; Tan, T.; Lv, Y. Magnetic metal-organic frameworks as scaffolds for spatial co-location and positional assembly of multi-enzyme systems enabling enhanced cascade biocatalysis. RSC Adv. 2017, 7, 21205-21213. [CrossRef]

31. Sheldon, R.A. Characteristic features and biotechnological applications of cross-linked enzyme aggregates (CLEAs) Appl. Microbiol. Biotechnol. 2011, 92, 467-477. [CrossRef]

32. Wei, Q.; He, S.; Qu, J.; Xia, J. Synthetic Multienzyme Complexes Assembled on Virus-like Particles for Cascade Biosynthesis in Cellulo. Bioconjug. Chem. 2020, 31, 2413-2420. [CrossRef] [PubMed]

33. Seo, M.J.; Schmidt-Dannert, C. Organizing Multi-Enzyme Systems into Programmable Materials for Biocatalysis. Catalysts 2021, 11, 409. [CrossRef]

34. Abdallah, W.; Hong, X.; Banta, S.; Wheeldon, I. Microenvironmental effects can masquerade as substrate channelling in cascade biocatalysis. Curr. Opin. Biotechnol. 2022, 73, 233-239. [CrossRef] [PubMed]

35. Zhang, Y.; Tsitkov, S.; Hess, H. Proximity does not contribute to activity enhancement in the glucose oxidase-horseradish peroxidase cascade. Nat. Commun. 2016, 7, 13982. [CrossRef] [PubMed]

36. Cao, Y.; Li, X.; Xiong, J.; Wang, L.; Yan, L.T.; Ge, J. Investigating the origin of high efficiency in confined multienzyme catalysis. Nanoscale 2019, 11, 22108-22117. [CrossRef]

37. Tretter, L.; Adam-Vizi, V. Alpha-ketoglutarate dehydrogenase: A target and generator of oxidative stress. Phil. Trans. R Soc. B. 2005, 360, 2335-2345. [CrossRef]

38. Garrett, R.H.; Grisham, C.M. Biochemistry; Cengage Learning: Belmont, CA, USA, 2008.

39. Frank, R.A.W.; Price, A.J.; Northrop, F.D.; Perham, R.N.; Luisi, B.F. Crystal Structure of the E1 Component of the Escherichia coli 2-Oxoglutarate Dehydrogenase Multienzyme Complex. J. Mol. Biol. 2007, 368, 639-651. [CrossRef]

40. Perham, R.N. Domains, motifs, and linkers in 2-oxo acid dehydrogenase multienzyme complexes: A paradigm in the design of a multifunctional protein. Biochemistry 1991, 30, 8501-8512. [CrossRef]

41. Perham, R.N. Swinging Arms and Swinging Domains in Multifunctional Enzymes: Catalytic Machines for Multistep Reactions. Annu. Rev. Biochem. 2000, 69, 961-1004. [CrossRef] 
42. Reed, L.J. A Trail of Research from Lipoic Acid to $\alpha$-Keto Acid Dehydrogenase Complexes. J. Biol. Chem. 2001, 276, 38329-38336. [CrossRef]

43. Murphy, G.E.; Jensen, G.J. Electron Cryotomography of the E. coli Pyruvate and 2-Oxoglutarate Dehydrogenase Complexes. Structure 2005, 13, 1765-1773. [CrossRef] [PubMed]

44. Kato, M.; Wynn, R.M.; Chuang, J.L.; Brautigam, C.A.; Custorio, M.; Chuang, D.T. A synchronized substrate-gating mechanism revealed by cubic-core structure of the bovine branched-chain a-ketoacid dehydrogenase complex. Eur. Mol. Biol. Organ. 2006, 25, 5983-5994. [CrossRef] [PubMed]

45. Izard, T.; Aevarsson, A.; Allen, M.D.; Westphal, A.H.; Perham, R.N.; de Kok, A.; Hol, W.G. Principles of quasi-equivalence and Euclidean geometry govern the assembly of cubic and dodecahedral cores of pyruvate dehydrogenase complexes. Proc. Natl. Acad. Sci. USA 1999, 96, 1240-1250. [CrossRef] [PubMed]

46. Mattevi, A.; Obmolova, G.; Kalk, K.H.; Teplyakov, A.; Hol, W.G. Crystallographic analysis of substrate binding and catalysis in dihydrolipoyl transacetylase (E2p). Biochemistry 1993, 32, 3887-3901. [CrossRef]

47. Milne, J.L.S.; Wu, X.; Borgnia, M.J.; Lengyel, J.S.; Brooks, B.R.; Shi, D.; Perham, R.N.; Subramaniam, S. Molecular structure of a 9-MDa icosahedral pyruvate dehydrogenase subcomplex containing the E2 and E3 enzymes using cryoelectron microscopy. J. Biol. Chem. 2006, 281, 4364-4370. [CrossRef]

48. Chandrasekhar, K.; Wang, J.; Arjunan, P.; Sax, M.; Park, Y.H.; Nemeria, N.S.; Kumaran, S.; Song, J.; Jordan, F.; Furey, W. Insight to the interaction of the dihydrolipoamide acetyltransferase (E2) core with the peripheral components in the Escherichia coli pyruvate dehydrogenase complex via multifaceted structural approaches. J. Biol. Chem. 2013, 288, 15402-15417. [CrossRef]

49. Andi, B.; Soares, A.S.; Shi, W.; Fuchs, M.R.; McSweeney, S.; Liu, Q. Structure of the dihydrolipoamide succinyltransferase catalytic domain from Escherichia coli in a novel crystal form: A tale of a common protein crystallization contaminant. Acta Cryst. Sect. F Struct. Biol. Commun. 2019, 75, 616-624. [CrossRef]

50. Wagenknecht, T.; Grassucci, R.; Schaak, D. Cryoelectron microscopy of frozen-hydrated $\alpha$-ketoacid dehydrogenase complexes from Escherichia coli. J. Biol. Chem. 1990, 265, 22402-22408. [CrossRef]

51. Wagenknecht, T.; Grassucci, R.; Berkowitz, J.; Forneris, C. Configuration of interdomain linkers in pyruvate dehydrogenase complex of Escherichia coli as determined by cryoelectron microscopy. J. Struct. Biol. 1992, 109, 70-77. [CrossRef]

52. Škerlová, J.; Berndtsson, J.; Nolte, H.; Ott, M.; Stenmark, P. Structure of the native pyruvate dehydrogenase complex reveals the mechanism of substrate insertion. Nat. Commun. 2021, 12, 5277. [CrossRef]

53. Bezerra, G.A.; Foster, W.R.; Bailey, H.J.; Hicks, K.G.; Sauer, S.W.; Dimitrov, B.; McCorvie, T.J.; Okun, J.G.; Rutter, J.; Kölker, S.; et al. Crystal structure and interaction studies of human DHTKD1 provide insight into a mitochondrial megacomplex in lysine catabolism. IUCrJ. 2020, 7, 693-706. [CrossRef] [PubMed]

54. Nagy, B.; Polak, M.; Ozohanics, O.; Zambo, Z.; Szabo, E.; Hubert, A.; Jordan, F.; Novaček, J.; Adam-Vizi, V.; Ambrus, A. Structure of the Dihydrolipoamide Succinyltransferase (E2) Component of the Human $\alpha$-ketoglutarate dehydrogenase complex (hKGDHc) revealed by cryo-EM and Cross-linking mass spectrometry: Implications for the overall hKGDHc structure. Free Radic. Biol. Med. 2020, 159, S29-S30. [CrossRef]

55. Reed, L.J.; Koike, M.; Levitch, M.E.; Leach, F.R. Studies on the nature and reactions of protein-bound Lipoic acid. J. Biol. Chem. 1958, 232, 143-158. [CrossRef]

56. Reed, L.J. Multienzyme complexes. Acc. Chem. Res. 1974, 7, 40-46. [CrossRef]

57. Miles, J.S.; Guest, J.R.; Radford, S.E.; Perham, R.N. Investigation of the mechanism of active site coupling in the pyruvate dehydrogenase multienzyme complex of Escherichia coli by protein engineering. J. Mol. Biol. 1988, 202, 97-106. [CrossRef]

58. Texter, F.L.; Radford, S.E.; Laue, E.D.; Perham, R.N.; Miles, J.S.; Guest, J.R. Site-directed mutagenesis and proton NMR spectroscopy of an interdomain segment in the pyruvate dehydrogenase multienzyme complex of Escherichia coli. Biochemistry 2002, 27, 289-296. [CrossRef] [PubMed]

59. Prajapati, S.; Haselbach, D.; Wittig, S.; Patel, M.S.; Chari, A.; Schmidt, C.; Stark, H.; Tittmann, K. Structural and Functional Analyses of the Human PDH Complex Suggest a "Division-of-Labor" Mechanism by Local E1 and E3 Clusters. Structure 2019, 27, 1124-1136.e4. [CrossRef] [PubMed]

60. Niebisch, A.; Kabus, A.; Schultz, C.; Weil, B.; Bott, M. Corynebacterial protein kinase G controls 2-oxoglutarate dehydrogenase activity via the phosphorylation status of the OdhI protein. J. Biol. Chem. 2006, 281, 12300-12307. [CrossRef]

61. Wagner, T.; Bellinzoni, M.; Wehenkel, A.; O'Hare, H.M.; Alzari, P.M. Functional plasticity and allosteric regulation of $\alpha-$ ketoglutarate decarboxylase in central mycobacterial metabolism. Chem. Biol. 2011, 18, 1011-1020. [CrossRef] [PubMed]

62. Hoffelder, M.; Raasch, K.; Van Ooyen, J.; Eggeling, L. The E2 domain of OdhA of Corynebacterium glutamicum has succinyltransferase activity dependent on lipoyl residues of the acetyltransferase AceF. J. Bacteriol. 2010, 192, 5203-5211. [CrossRef] [PubMed]

63. Nemeria, N.S.; Gerfen, G.; Nareddy, P.; Yang, L.; Zhang, X.; Szostak, M.; Jordan, F. The mitochondrial 2-oxoadipate and 2oxoglutarate dehydrogenase complexes share their E2 and E3 components for their function and both generate reactive oxygen species. Free Radic. Biol. Med. 2018, 115, 136-145. [CrossRef] [PubMed]

64. Nemeria, N.S.; Gerfen, G.; Guevara, E.; Nareddy, P.R.; Szostak, M.; Jordan, F. The human Krebs cycle 2-oxoglutarate dehydrogenase complex creates an additional source of superoxide/hydrogen peroxide from 2-oxoadipate as alternative substrate. Free Radic. Biol. Med. 2017, 108, 644-654. [CrossRef] [PubMed] 
65. Leandro, J.; Khamrui, S.; Wang, H.; Suebsuwong, C.; Nemeria, N.S.; Huynh, K.; Moustakim, M.; Secor, C.; Wang, M.; Dodatko, T.; et al. Inhibition and Crystal Structure of the Human DHTKD1-Thiamin Diphosphate Complex. ACS Chem. Biol. 2020, 15, 2041-2047. [CrossRef] [PubMed]

66. Knapp, J.E.; Carroll, D.; Lawson, J.E.; Ernst, S.R.; Reed, L.J.; Hackert, M.L. Expression, purification, and structural analysis of the trimeric form of the catalytic domain of the Escherichia coli dihydrolipoamide succinyltransferase. Protein. Sci. 2000, 9, 37-48. [CrossRef] [PubMed]

67. Nemeria, N.S.; Ambrus, A.; Patel, H.; Gerfen, G.; Adam-Vizi, V.; Tretter, L.; Zhou, J.; Wang, J.; Jordan, F. Human 2-oxoglutarate dehydrogenase complex E1 component forms a thiamin-derived radical by aerobic oxidation of the enamine intermediate. J. Biol. Chem. 2014, 289, 29859-29873. [CrossRef]

68. Shim, D.J.; Nemeria, N.S.; Balakrishnan, A.; Patel, H.; Song, J.; Wang, J.; Jordan, F.; Farinas, E.T. Assignment of function to histidines 260 and 298 by engineering the E1 component of the Escherichia coli 2-oxoglutarate dehydrogenase complex; Substitutions that lead to acceptance of substrates lacking the 5-carboxyl group. Biochemistry 2011, 50, 7705-7709. [CrossRef] [PubMed]

69. Guevara, E.L. Different Modes of Activation of the Four Regulatory Pyruvate Dehydrogenase Kinases by the E2 and E3 Binding Protein Components of the Human Pyurvate Dehydrogenase Complex. Ph.D. Thesis, Rutgers University, Newark, NJ, USA, 2017.

70. Chakraborty, J. Engineering of Escherichia coli 2-Oxoglutarate Dehydrogenase Complex with Mechanistic and Synthetic Goals. Ph.D. Thesis, New Jersey Institute of Technology, Newark, NJ, USA, 2019.

71. Baykal, A.; Chakraborty, S.; Dodoo, A.; Jordan, F. Synthesis with good enantiomeric excess of both enantiomers of alpha-ketols and acetolactates by two thiamin diphosphate-dependent decarboxylases. Bioorg. Chem. 2006, 34, 380-393. [CrossRef]

72. Nemeria, N.; Korotchkina, L.; McLeish, M.J.; Kenyon, G.L.; Patel, M.S.; Jordan, F. Elucidation of the Chemistry of EnzymeBound Thiamin Diphosphate Prior to Substrate Binding: Defining Internal Equilibria among Tautomeric and Ionization States. Biochemistry 2007, 46, 10739-10744. [CrossRef]

73. Polovnikova, E.S.; McLeish, M.J.; Sergienko, E.A.; Burgner, J.T.; Anderson, N.L.; Bera, A.K.; Jordan, F.; Kenyon, A.G.L.; Hasson, M.S. Structural and Kinetic Analysis of Catalysis by a Thiamin Diphosphate-Dependent Enzyme, Benzoylformate Decarboxylase. Biochemistry 2003, 42, 1820-1830. [CrossRef] [PubMed]

74. Meyer, D.; Walter, L.; Kolter, G.; Pohl, M.; Müller, M.; Tittmann, K. Conversion of Pyruvate Decarboxylase into an Enantioselective Carboligase with Biosynthetic Potential. J. Am. Chem. Soc. 2011, 133, 3609-3616. [CrossRef]

75. Beigi, M.; Waltzer, S.; Fries, A.; Eggeling, L.; Sprenger, G.A.; Müller, M. TCA cycle involved enzymes SucA and Kgd, as well as MenD: Efficient biocatalysts for asymmetric C-C bond formation. Org. Lett. 2013, 15, 452-455. [CrossRef] [PubMed]

76. Kasparyan, E.; Richter, M.; Dresen, C.; Walter, L.S.; Fuchs, G.; Leeper, F.J.; Wacker, T.; Andrade, S.L.A.; Kolter, G.; Pohl, M.; et al. Asymmetric Stetter reactions catalyzed by thiamine diphosphate-dependent enzymes. Appl. Microbiol. Biotechnol. 2014, 98, 9681-9690. [CrossRef] [PubMed]

77. Jordan, F. Current mechanistic understanding of thiamin diphosphate-dependent enzymatic reactions. Nat. Prod. Rep. 2003, 20, 184-201. [CrossRef] [PubMed]

78. Brandt, G.S.; Kneen, M.M.; Petsko, G.A.; Ringe, D.; McLeish, M.J. Active-site engineering of benzaldehyde lyase shows that a point mutation can confer both new reactivity and susceptibility to mechanism-based inhibition. J. Am. Chem. Soc. 2010, 132, 438-439. [CrossRef] [PubMed]

79. Hailes, H.C.; Rother, D.; Müller, M.; Westphal, R.; Ward, J.M.; Pleiss, J.; Vogel, C.; Pohl, M. Engineering stereoselectivity of ThDP-dependent enzymes. FEBS J. 2013, 280, 6374-6394. [CrossRef] [PubMed]

80. Baraibar, Á.G.; Von Lieres, E.; Wiechert, W.; Pohl, M.; Rother, D. Effective production of (S)- $\alpha$-hydroxy ketones: An reaction engineering approach. Top. Catal. 2014, 57, 401-411. [CrossRef]

81. Marsden, S.R.; McMillan, D.G.G.; Hanefeld, U. Assessing the Thiamine Diphosphate Dependent Pyruvate Dehydrogenase E1 Subunit for Carboligation Reactions with Aliphatic Ketoacids. Int. J. Mol. Sci. 2020, 21, 8641. [CrossRef]

82. Schapfl, M.; Baier, S.; Fries, A.; Ferlaino, S.; Waltzer, S.; Müller, M.; Sprenger, G.A. Extended substrate range of thiamine diphosphate-dependent MenD enzyme by coupling of two C-C-bonding reactions. Appl. Microbiol. Biotechnol. 2018, 102, 8359-8372. [CrossRef]

83. Kulig, J.; Sehl, T.; Mackfeld, U.; Wiechert, W.; Pohl, M.; Rother, D. An Enzymatic 2-Step Cofactor and Co-Product Recycling Cascade towards a Chiral 1,2-Diol. Part I: Cascade Design. Adv. Synth. Catal. 2019, 361, 2607-2615. [CrossRef]

84. Nilsson, U.; Meshalkina, L.; Lindqvist, Y.; Schneidere, G. Examination of substrate binding in thiamin diphosphate-dependent transketolase by protein crystallography and site-directed mutagenesis. J. Biol. Chem. 1997, 272, 1864-1869. [CrossRef]

85. Hibbert, E.G.; Senussi, T.; Costelloe, S.J.; Lei, W.; Smith, M.E.; Ward, J.M.; Hailes, H.C.; Dalby, P.A. Directed evolution of transketolase activity on non-phosphorylated substrates. J. Biotechnol. 2007, 131, 425-432. [CrossRef] [PubMed]

86. Smith, M.E.B.; Hibbert, E.G.; Jones, A.B.; Dalby, P.A.; Hailesa, H.C. Enhancing and Reversing the Stereoselectivity of Escherichia coli Transketolase via Single-Point Mutations. Adv. Synth. Catal. 2008, 350, 2631-2638. [CrossRef]

87. Engel, S.; Vyazmensky, M.; Geresh, S.; Barak, Z.; Chipman, D.M. Acetohydroxyacid synthase: A new enzyme for chiral synthesis of R-phenylacetylcarbinol. Biotechnol. Bioeng. 2003, 83, 833-840. [CrossRef] [PubMed]

88. Chipman, D.M.; Duggleby, R.G.; Tittmann, K. Mechanisms of acetohydroxyacid synthases. Curr. Opin. Chem. Biol. 2005, 9, 475-481. [CrossRef] [PubMed] 
89. Vyazmensky, M.; Steinmetz, A.; Meyer, D.; Golbik, R.; Barak, E.; Tittmann, K.; Chipman, D.M. Significant Catalytic Roles for Glu47 and Gln 110 in All Four of the CÀC Bond-Making and-Breaking Steps of the Reactions of Acetohydroxyacid Synthase II. Biochemistry 2011, 50, 3250-3260. [CrossRef]

90. Lingen, B.; Kolter-Jung, D.; Dünkelmann, P.; Feldmann, R.; Grötzinger, J.; Pohl, M.; Müller, M. Alteration of the substrate specificity of benzoylformate decarboxylase from Pseudomonas putida by directed evolution. ChemBioChem. 2003, 4, 721-726. [CrossRef]

91. Siegert, P.; McLeish, M.; Baumann, M.; Iding, H.; Kneen, M.M.; Kenyon, G.L.; Pohl, M. Exchanging the substrate specificities of pyruvate decarboxylase from Zymomonas mobilis and benzoylformate decarboxylase from Pseudomonas putida. Protein. Eng. Des. Sel. 2005, 18, 345-357. [CrossRef]

92. De María, P.D.; Pohl, M.; Gocke, D.; Gröger, H.; Trauthwein, H.; Stillger, T.; Walter, L.; Müller, M. Asymmetric synthesis of aliphatic 2-hydroxy ketones by enzymatic carboligation of aldehydes. Eur. J. Org. Chem. 2007, 2009, 2940-2944. [CrossRef]

93. Kurutsch, A.; Richter, M.; Brecht, V.; Sprenger, G.A.; Müller, M. MenD as a versatile catalyst for asymmetric synthesis. J. Mol. Catal. B Enzym. 2009, 61, 56-66. [CrossRef]

94. Beigi, M.; Loschonsky, S.; Lehwald, P.; Brecht, V.; Andrade, S.L.A.; Leeper, F.J.; Hummeld, W.; Müller, M. Organic \& Biomolecular Chemistry $\alpha$-Hydroxy- $\beta$-keto acid rearrangement-decarboxylation: Impact on thiamine diphosphate-dependent enzymatic transformation. Org. Biomol. Chem. 2013, 11, 252.

95. Sergienko, E.A.; Jordan, F. Catalytic acid-base groups in yeast pyruvate decarboxylase. 3. A steady-state kinetic model consistent with the behavior of both wild-type and variant enzymes at all relevant $\mathrm{pH}$ values. Biochemistry 2001, 40, 7382-7403. [CrossRef]

96. Nemeria, N.; Tittmann, K.; Joseph, E.; Zhou, L.; Vazquez-Coll, M.B.; Arjunan, P.; Hübner, G.; Furey, W.; Jordan, F. Glutamate 636 of the Escherichia coli Pyruvate Dehydrogenase-E1 Participates in Active Center Communication and Behaves as an Engineered Acetolactate Synthase with Unusual Stereoselectivity. J. Biol. Chem. 2005, 280, 21473-21482. [CrossRef] [PubMed]

97. Patel, H.; Shim, D.J.; Farinas, E.T.; Jordan, F. Investigation of the donor and acceptor range for chiral carboligation catalyzed by the E1 component of the 2-oxoglutarate dehydrogenase complex. J. Mol. Catal. B Enzym. 2013, 98, 42-45. [CrossRef] [PubMed]

98. Jordan, F.; Nemeria, N.S.; Balakrishnan, A.; Chakraborty, J.; Guevara, E.; Nareddy, P.; Patel, H.; Shim, D.J.; Wang, J.; Yang, L.; et al. An Update on Developments in the Field of Thiamin Diphosphate-Dependent Enzymes. Compr. Nat. Prod. III 2020, 4, 58-110.

99. Knapp, J.E.; Mitchell, D.T.; Yazdi, M.A.; Ernst, S.R.; Reed, L.J.; Hackert, M.L. Crystal structure of the truncated cubic core component of the Escherichia coli 2-oxoglutarate dehydrogenase multienzyme complex. J. Mol. Biol. 1998, 280, 655-668. [CrossRef] [PubMed]

100. Hendle, J.; Mattevi, A.; Westphal, A.H.; Spee, J.; De Kok, A.; Teplyakov, A.; Hol, W.G. Crystallographic and Enzymatic Investigations on the Role of Ser558, His610, and Asn614 in the Catalytic Mechanism of Azotobacter vinelandii Dihydrolipoamide Acetyltransferase (Elp)1. Biochemistry 1995, 34, 4287-4298. [CrossRef]

101. Yu, X.; Hiromasa, Y.; Tsen, H.; Stoops, J.K.; Roche, T.E.; Zhou, Z.H. Structures of the Human Pyruvate Dehydrogenase Complex Cores: A Highly Conserved Catalytic Center with Flexible N-Terminal Domains. Structure 2008, 16, 104-114. [CrossRef]

102. Kyrilis, F.L.; Semchonok, D.A.; Skalidis, I.; Tüting, C.; Hamdi, F.; O’Reilly, F.J.; Rappsilber, J.; Kastritis, P.L. Integrative structure of a 10-megadalton eukaryotic pyruvate dehydrogenase complex from native cell extracts. Cell Rep. 2021, 34, 108727. [CrossRef]

103. Guest, J.R. Functional implications of structural homologies between chloramphenicol acetyltransferase and dihydrolipoamide acetyltransferase. FEMS Microbiol. Lett. 1987, 44, 417-422. [CrossRef]

104. Shaw, W.V.; Leslie, A.G.W. Chloramphenicol Acetyltransferase. Annu. Rev. Biophys. Biophys. Chem. 1991, 20, 363-386. [CrossRef]

105. Carter, P.; Wells, J.A. Dissecting the catalytic triad of a serine protease. Nature 1988, 332, 564-568. [CrossRef] [PubMed]

106. Chakraborty, J.; Nemeria, N.S.; Farinas, E.; Jordan, F. Catalysis of transthiolacylation in the active centers of dihydrolipoamide acyltransacetylase components of 2-oxo acid dehydrogenase complexes. FEBS Open Bio. 2018, 8, 880-896. [CrossRef] [PubMed]

107. Lewendon, A.; Murray, I.A.; Shaw, W.V.; Gibbs, M.R.; Leslie, A.G.W. Replacement of catalytic histidine-195 of chloramphenicol acetyltransferase: Evidence for a general base role for glutamate. Biochemistry 1994, 33, 1944-1950. [CrossRef] [PubMed]

108. Russell, G.C.; Guest, J.R. Site-directed mutagenesis of the lipoate acetyltransferase of Escherichia coli. Proc. R Soc. B Biol. Sci. 1991, 243, 155-160.

109. Russell, G.C.; Guest, J.R. Sequence similarities within the family of dihydrolipoamide acyltransferases and discovery of a previously unidentified fungal enzyme. Biochim. Biophys. Acta BBA Protein. Struct. Mol. 1991, 1076, 225-232. [CrossRef]

110. Chakraborty, J.; Nemeria, N.S.; Zhang, X.; Nareddy, P.R.; Szostak, M.; Farinas, E.; Jordan, F. Engineering 2- oxoglutarate dehydrogenase to a 2-oxo aliphatic dehydrogenase complex by optimizing consecutive components. AIChE J. 2020, 66, e16769. [CrossRef]

111. Pettersen, E.F.; Goddard, T.D.; Huang, C.C.; Couch, G.S.; Greenblatt, D.M.; Meng, E.C.; Ferrin, T.E. UCSF Chimera-A visualization system for exploratory research and analysis. J. Comput. Chem. 2004, 25, 1605-1612. [CrossRef]

112. Jumper, J.; Evans, R.; Pritzel, A.; Green, T.; Figurnov, M.; Ronneberger, O.; Tunyasuvunakool, K.; Bates, R.; Žídek, A.; Potapenko, A.; et al. Highly accurate protein structure prediction with AlphaFold. Nature 2021, 596, 583-589. [CrossRef]

113. Choi, J.-M.; Han, S.-S.; Kim, H.-S. Industrial applications of enzyme biocatalysis: Current status and future aspects. Biotechnol. Adv. 2015, 33, 1443-1454. [CrossRef]

114. Guan, L.-J.; Ohtsuka, J.; Okai, M.; Miyakawa, T.; Mase, T.; Zhi, Y.; Hou, F.; Ito, N.; Iwasaki, A.; Yasohara, Y.; et al. A new target region for changing the substrate specificity of amine transaminases. Sci. Rep. 2015, 5, 10753. [CrossRef]

115. Cobb, R.E.; Chao, R.; Zhao, H. Directed Evolution: Past, Present and Future. AIChE J. 2013, 59, 1432-1440. [CrossRef] [PubMed] 
116. Desai, A.A. Sitagliptin Manufacture: A Compelling Tale of Green Chemistry, Process Intensification, and Industrial Asymmetric Catalysis. Angew. Chem. Int. Ed. 2011, 50, 1974-1976. [CrossRef] [PubMed]

117. Kazemi, M.; Shiri, L. Thioesters synthesis: Recent adventures in the esterification of thiols. J. Sulfur. Chem. $2015,36,613-623$. [CrossRef]

118. Hutchison, C.A.; Chuang, R.-Y.; Noskov, V.N.; Assad-Garcia, N.; Deerinck, T.J.; Ellisman, M.H.; Gill, J.; Kannan, K.; Karas, B.J.; Ma, L.; et al. Design and synthesis of a minimal bacterial genome. Science 2016, 351, aad6253. [CrossRef] [PubMed]

119. Leveson-Gower, R.B.; Mayer, C.; Roelfes, G. The importance of catalytic promiscuity for enzyme design and evolution. Nat. Rev. Chem. Nat. Res. 2019, 3, 687-705. [CrossRef]

120. Currin, A.; Swainston, N.; Day, P.J.; Kell, D.B. Synthetic biology for the directed evolution of protein biocatalysts: Navigating sequence space intelligently. Chem. Soc. Rev. R. Soc. Chem. 2015, 44, 1172-1239. [CrossRef]

121. Yuen, C.M.; Liu, D.R. Dissecting protein structure and function using directed evolution. Nat. Methods 2007, 4, 995-997. [CrossRef]

122. Newton, M.S.; Arcus, V.L.; Gerth, M.L.; Patrick, W.M. Enzyme evolution: Innovation is easy, optimization is complicated. Curr. Opin. Struct. Biol. 2018, 48, 110-116. [CrossRef]

123. Arnold, F.H. Directed Evolution: Bringing New Chemistry to Life. Angew. Chem. Int. Ed. 2018, 57, 4143-4148. [CrossRef]

124. Khosla, C.; Harbury, P.B. Detection of modular enzymes. Nature 2001, 409, 247-252. [CrossRef] 